\title{
On Social Health: Conceptualization, Correlates and Patterning
}

\author{
David Matthew Doyle ${ }^{1} \&$ Bruce G. Link ${ }^{2}$ \\ ${ }^{1}$ Department of Psychology, University of Exeter \\ ${ }^{2}$ School of Public Policy and Department of Sociology, University of California, Riverside
}

\begin{abstract}
Author Note
Correspondence concerning this paper should be addressed to David Matthew Doyle, Department of Psychology, University of Exeter, Washington Singer Laboratories, Perry Road, Exeter, EX4 4QG, Devon, United Kingdom. E-mail: d.doyle@exeter.ac.uk.
\end{abstract}




\begin{abstract}
Drawing upon extensive literature on the importance of social relationships from across social science and health disciplines, we propose a strong conceptualization of social health as a dynamic and multifaceted construct with the ability to expand and focus theory, research and practice. We define social health as the perceived and actual availability and quality of one's various social relationships. Using this conceptualization, we demonstrate how a tripartite model of health, situated within the human body (and mind), best explains well-documented interrelationships between physical, psychological and social aspects of health. In order to describe the utility and importance of social health, we discuss its significance to understanding and addressing population health concerns, especially health inequalities, as well as recent major global events, including the rise of "deaths of despair" and the COVID-19 pandemic. By renewing research on social health under the framework presented herein, scholars can unify disparate lines of work on constructs ranging from loneliness and social integration to close relationship quality and social capital. Moreover, we argue that adoption of the concept of social health is critical to the success of nations, states and health systems across societies in guaranteeing an optimal state of health for all.
\end{abstract}

Keywords: social health, social relationships, loneliness, social integration, health disparities 


\section{On Social Health: Conceptualization, Correlates and Patterning}

No more fiendish punishment could be devised, were such a thing physically possible, than that one should be turned loose in society and remain absolutely unnoticed by all the members thereof. If no one turned round when we entered, answered when we spoke, or minded what we did, but if every person we met 'cut us dead,' and acted as if we were non-existing things, a kind of rage and impotent despair would ere long well up in us, from which the cruelest bodily tortures would be a relief; for these would make us feel that, however bad might be our plight, we had not sunk to such a depth as to be unworthy of attention at all (James, 1890, pp. 293-294).

Perhaps the most intuitive way to imagine what constitutes a healthy life is to think about waking up in the morning and feeling capable and willing to get out of bed versus not. Everyone has had the experience of waking up either physically sick or mentally down, and the idea of getting out of bed seems both impossible and unappealing (we would rather wrap ourselves in our blankets and hibernate until we feel better). Now imagine waking up and thinking that no one in the world cares about our presence in it. A similar instinct would take hold, and that may be the essence of social health. Here we seek to elaborate upon this intuitive understanding, proposing that social health, the perceived and actual availability and quality of one's various social relationships, is an integral part of what health is. Humans evolved as a social species (Bowlby, 1973; Brewer \& Caporeal, 1990; Buss \& Kenrick, 1998; Dunbar, 1998) and it is pointless to assert that understanding human health is possible when social dimensions are excised from our definitions of health. It is therefore surprising that some researchers and scholars have aimed to understand human health divorced from its social aspect (Wade \& 
Halligan, 2004). We argue that social health is a critical dimension of overall health, along with psychological and physical health, and that a comprehensive, tripartite conceptualization of health (displayed in Figure 1) will expand and focus theory, research and practice across disciplines. Rather than portraying social relationships exclusively as predictors of other health outcomes (or as moderators of effects of other constructs, such as stress, on health), we argue that social relationships should be examined as a core component of health (i.e., a health outcome) in their own right. Adoption of the concept of social health across social science and health fields will facilitate a more holistic understanding of human potential and the central importance of social relationships to a healthy and fulfilling human life. Such a conceptualization is key to the success of nations, states and health systems across societies in guaranteeing an optimal state of health for all. In the following sections, a framework for the conceptualization of social health is established, correlates of this construct are discussed and attention is paid to its distribution, or social patterning, throughout populations.

\section{The Concept of Health through History}

Our conceptualization of social health emerges from the history of health's conceptualization in previous eras. As we will see, social health has been integral to various conceptualizations of health across the broad sweep of human history, a circumstance that favors, as we see it, our reintroduction of its importance in the contemporary era. Definitions and conceptualizations of health are not static, but evolve continuously along with advances in theory and scientific knowledge as well as trends in socio-political contexts (Larson, 1999). Some of the earliest attempts to systematically understand and define health in the Western Hemisphere considered the balance of four bodily substances, or humors: blood, phlegm, black bile and yellow bile (Sigerist, 1943). Proponents of this view, including the influential Greek 
philosophers Hippocrates and Galen, considered health to result from equilibrium among the humors. When disequilibrium was introduced through an imbalance of the humors, disease was thought to result. Importantly, these early medical philosophers posited that equilibrium among the humors was maintained via interactions between an individual and his or her environment, both physical and social (Breslow, 2006; Noack, 1987). This conceptualization is also found in the seminal writings of early Eastern philosophies, including Buddhism and Taoism, which similarly view health as a state of harmony and balance (Chan et al., 2002; Wallace \& Shapiro, 2006). Moreover, Eastern philosophies, such as Confucianism, emphasize the central role of well-functioning social relationships in maintaining a healthy and balanced life (Triandis, 1995; Yum, 1988). Thus, for extensive periods of time in both Eastern and Western thought, social health was considered an integral part of what health is. While Eastern philosophy and medicine to a large extent retained the principle of equilibrium (including equilibrium with the social environment; $\mathrm{Ng}$ et al., 2008), over time this approach has fallen out of favor in the majority of the Western hemisphere.

Scientific progress brought about many vital improvements in medicine and medical practice, but the emerging view of the body during the Scientific Revolution of the seventeenth century likened it to a machine that could be mended when component parts ceased to function "properly." Disease (or ill-health), therefore, became synonymous with disruption of the system (Larson, 1999). Within the United States, the biomedical model of health dominated throughout the first three quarters of the twentieth century (Engel, 1977; Wade \& Halligan, 2004). This model is situated within an understanding of health that centers on germ theory, which stipulates that disease results from the presence of specific micro-organisms capable of contaminating the body (Evans, 1976). According to the biomedical model, health can be defined as the absence of 
bodily disease or disability (Breslow, 1972; Guillemin \& Barnard, 2015; Larson, 1999). While ascendant for a relatively brief period in the broad scope of history, this restricted biology-only model leaves little room for constructs such as psychological and social health that fall outside a narrowly conceptualized physiological realm. However, as numerous scholars have observed (e.g., Johnson, 2013; Susser \& Susser, 1996), the biomedical model is relatively better suited to explaining infectious diseases (the predominant causes of death and disability in the first half of the twentieth century) compared to chronic diseases (the predominant causes of death and disability in high- and middle-income countries today). As a consequence, as historical trends in patterns of disease and disability evolved, new broader approaches to health and medicine became necessary.

A watershed period for expansion of definitions of health came with the creation of the World Health Organization (WHO) and the constitution it adopted. According to this influential global organization, health could be defined as "a state of complete physical, mental and social well-being and not merely the absence of disease or infirmity" (WHO, 1948). In proposing this definition, the WHO affirmed the necessity of understanding constructs and conditions that lie outside the physical realm. During the second half of the twentieth century, another important development came with the introduction of the biopsychosocial model of health (Engel, 1977). The biopsychosocial model was proposed to theoretically and conceptually connect social factors to biological and psychological processes (Engel, 1977; Guillemin \& Barnard, 2015; Suls \& Rothman, 2004). Like the WHO definition, the biopsychosocial model sprung out of the need for a more comprehensive way to understand factors that constitute health and illness, especially chronic diseases of aging (Lindau et al., 2003). Reflecting a growing recognition of the importance of social relationships to health, Figure 2 shows results of a PubMed search (Sperr, 
2016) illustrating an increase in the proportion of publications in medical journals including the term "social relationship" over time. Indeed, the proportion of publications including this term appears to have begun increasing in the 1980's, after the introduction of the biopsychosocial model and then the publication of a seminal paper by House and colleagues on social relationships and health (House, Landis, \& Umberson, 1988), with more marked increases appearing sometime in the 2000's. Despite these advances in expanding the definition of health, the biomedical model continues to heavily influence researchers and practitioners in the health sciences today (Alonso, 2004).

Scholars interested in human well-being and positive psychology (whose work reaches beyond negative states of being) have rapidly accepted social relationships as a core component of health (e.g., Keyes, 1998; Larson, 1993, 1996; Ryff \& Singer, 2000). Drawing upon sociological work by theorists such as Durkheim and Marx, Keyes (1998) argued that researchers tend to emphasize private (e.g., psychological) over public (e.g., social) aspects of well-being; yet both are critical for understanding human health and, especially, thriving. This idea was elaborated and expanded upon in a theoretical and empirical review of interpersonal flourishing (Ryff \& Singer, 2000), in which the authors argued that, "Central among the core criterial goods comprising optimal living is having quality ties to others" (p. 31).

From this brief historical perspective, it is clear that, with the exception of a relatively recent narrow biological emphasis that is already eroding, conceptualizations of health have historically incorporated social elements. Therefore, the history of definitions of health has been to point toward social health as a core criterion. Our position is that not only researchers across the social and biological sciences, but health systems across communities and nations will benefit from the adoption of social health as a component of overall health in theory and 
practice. To help propel this process, we begin by outlining our conceptualization of social health drawn with reference to previous literature.

\section{Conceptualizing Social Health}

We argue that it is now necessary for contemporary researchers to resolutely acknowledge the fundamental position of social relationships in human health and well-being. In contending that social health should be considered alongside physical and psychological health as a core component of overall health and well-being, a particularly compelling argument is that social health is tightly bound up with life expectancy. As human beings, the need for affiliation and social connection is fundamental to survival, not only of the individual but also of the species (Atzil et al., 2018; Baumeister \& Leary, 1995; Bowlby, 1973; Maslow, 1943; SnyderMackler et al., 2020). Decades of evidence from observational studies, including longitudinal research with adjustment for a plethora of potential confounders, has tied indicators of poor social health to mortality risk (Holt-Lunstad et al., 2015). Overall, the strength of the association between poor social health and mortality is on par with established clinical risk factors, such as elevated blood pressure and high cholesterol (Holt-Lunstad et al., 2010; Pantell et al., 2013). In one example of a connection between social health and mortality, there is evidence that the death of a loved one (e.g., spouse) leads to increased mortality risk for the widowed person (Elwert \& Christakis, 2008). In the most extreme cases, the death of a close relational partner can lead to ballooning of the heart, clinically referred to as Takotsubo cardiomyopathy, which can cause sudden death in otherwise physically and psychologically healthy people (Akashi et al., 2008; Templin et al., 2015). This condition is sometimes colloquially referred to as "broken heart syndrome" (Efferth et al., 2017). Moreover, poor social health may be linked to mortality via its contribution to suicide risk. Over a century ago, Durkheim (1897) conducted seminal research 
on this topic, showing that levels of social integration, or close involvement with others, influence suicide rates. He classified this phenomenon as anomic suicide because he posited that it resulted from feelings of alienation and disconnection from society. Further research has continued to confirm that interpersonal factors, including loneliness and lack of social belonging, play an important role in suicide risk (Van Orden et al., 2010). Moreover, recent evidence suggests that ostracism, or social exclusion, can trigger suicidal thoughts in otherwise healthy people (Chen et al., 2020). It is relevant and troubling to note that mortality from suicide and unintentional overdose (sometimes referred to as "deaths of despair;" Case \& Deaton, 2020) has been increasing at staggering rates in recent years in the United States and other high-income countries (Bohnert \& Ilgen, 2019), perhaps driven in part by loneliness and social isolation (Jeste et al., 2020). Solitary confinement in prison, an extreme form of social isolation imposed by legal authority, has also been shown to increase mortality risk, both from suicide as well as other causes (Luigi et al., 2020). Across different circumstances in which social health is abruptly and sharply challenged, the very fact of life itself is compromised in many ways that speak strongly to the central importance of social health.

In terms of health, life is the sine qua non, in that it is impossible to say one is living a healthy life if one is, in fact, not alive. However, health is not only about being alive, but also the quality of engagement in and enjoyment of daily activities (Guyatt et al., 1995), generally classified as health-related quality of life. As with chronic physical and mental illnesses, there is little doubt that poor social health impairs health-related quality of life (Lu et al., 2020; National Academy of Sciences, Engineering, and Medicine, 2020). Among other consequences, poor social health leads to functional limitations and decline (e.g., Buchman et al., 2010; Perissinotto et al., 2012), increases sleep disturbance (Griffin et al., 2020), decreases cognitive ability (Boss 
et al., 2015) and impairs emotion regulation (e.g., Vanhalst et al., 2018; van Roekel et al., 2014). Research suggests that the damaging effects of social isolation on health-related quality of life are of a magnitude that is clinically significant and independent of physical comorbidities and depression as well as various demographic factors (Hawton et al., 2011). One clinical example is a recently classified form of extreme social withdrawal, labelled "hikikomori," that was first identified in Japan (Kato et al., 2018). This condition typically manifests among young adults who withdraw into their own homes, rarely leaving or interacting in-person with others. By definition, clinical cases of hikikomori involve significant functional impairment and/or distress associated with social isolation (Kato et al., 2019), with one study (Chan \& Lo, 2014) demonstrating that the degree of social withdrawal is predictive of the level of impairment in health-related quality of life. In contrast to voluntary social withdrawal, ostracism (or involuntary social exclusion) is one of the most painful and distressing human experiences (Williams, 2007), with some research even suggesting that ostracism is more damaging for wellbeing than harassment (e.g., O’Reilly et al., 2015). Overall, social isolation is so detrimental to quality of life (Luigi et al., 2020) that the United Nations (UN) and other international organizations have called for the abolition or extreme restriction of the use of solitary confinement in prisons, viewing the practice as an affront to human rights (Cloud et al., 2015; Shalev, 2014). In sum, as in our consideration of mortality following disruption to social health, we see that when social health is inadequate or severely challenged either voluntarily or involuntarily, quality of life is often severely impaired as a result.

For these as well as other reasons, poor social health has enormous costs to society, both social as well as economic (Mihalopoulos et al., 2020). For example, one study of the cost of illness (Fulton \& Jupp, 2015) estimated that chronic loneliness costs an average of $£ 11,725$ 
(equivalent to approximately $\$ 16,000$ ) per person over a medium term (i.e., 15 years), including a variety of both medical (e.g., in-patient costs) and non-medical costs (e.g., costs of residential care). Similarly, estimates from a nationally representative sample in the Netherlands (Meisters et al., 2021) suggest that loneliness cost $€ 3,462,000,000$ (equivalent to approximately $\$ 4,200,000,000)$ in healthcare expenditure in 2017 . Generally, such estimates are conservative in that they cannot incorporate all of the various ways in which poor social health impairs life trajectories (e.g., worse educational and career prospects, lack of benefits and security related to marriage and family), yet the enormous costs to society are still readily apparent. Given the clear importance of social relationships to mortality and health-related quality of life as well as the social and economic costs associated with poor social health, the argument that social relationships form a core component of overall health needs to be heeded by researchers, practitioners, policy-makers and health systems. To do so, these parties need to be informed by a clear definition of social health in order to aid in addressing this critical element of human health and well-being, a key aim here.

\section{Defining Social Health}

In 1973, Russell observed that relatively little effort had gone into clarifying the meaning of social health since its inclusion in the WHO definition of health in 1948. In his work with health professionals and students, Russell (1973) ultimately determined that a consensus on the definition of social health was impossible to reach at the time. Over 40 years later, despite a few attempts across scientific disciplines (including psychology, psychiatry, behavioral medicine, sociology and epidemiology), not much progress has been made on this front.

Definitions of social health that do exist are infrequently cited, with researchers generally referring back to the WHO constitution to support their investigations of this construct in 
empirical studies. Furthermore, many important constructs that are closely related to social health (discussed in the following sections) have been siloed within their respective disciplines, with highly overlapping lines of research developing largely independently from one another. For these reasons, there is a pressing need to work toward a unifying framework which will allow researchers within and across disciplines who are interested in social health to share knowledge and speak fluently. Only in this way can scholars build a comprehensive and nuanced corpus of work on social health across disciplines. If researchers are to embrace social health as a component of overall health, it is vital to agree upon a common definition to serve as a springboard for future work.

Social health is defined here as the perceived and actual availability and quality of one's various social relationships. This definition was developed through a careful review of relevant literature and consideration of previous definitions offered by other researchers interested in social health and well-being (shown in Table 1). These definitions vary considerably but share some important overlapping features, discussed in detail in the following sections.

\section{Core Features of Social Health}

\section{Like other components of health, social health is conceptualized at the individual}

level. In delineating social health, it is necessary to demarcate clear boundaries. One such boundary involves the level at which social health is situated. We conceptualize social health as an individual attribute that, like physical and psychological health, is strongly influenced by the external social environment. As others have noted (e.g., Donald et al., 1978; Russell, 1973), there have been attempts to conceptualize social health exclusively as a property of societies. While this approach is not incorrect, it is inconsistent with predominant views of other forms of individual health. Physical and psychological health are typically viewed as properties of 
individuals. While these constructs may be measured at the societal or population level, this is generally done through an aggregate of individual-level data rather than attempting to forge indicators of properties of physical or psychological health that emerge at the level of the community or nation. It is therefore logical to mirror this conceptualization of health as a property of the individual in defining social health. As discussed later in this paper, societal factors certainly may be responsible for patterning social health, but social health is ultimately considered here to be a property of the individual. This approach is echoed in a number of definitions of social health, reviewed in Table 1, that include words such as "one's" or “individual's” (e.g., Donald et al., 1978; Keyes \& Shapiro, 2004; Larson, 1993; Russell, 1973).

A critique that has been leveled against social health is that it extends "beyond the skin"- that is, it is not entirely bound within the individual but is also a function of the social environment (e.g., Ware et al., 1981). For example, one may suffer poorer social health as a result of the death of a close relational partner (Lehman et al., 1987; Liu et al., 2019). While it is true that social health is affected by factors external to the individual, this critique is misguided and incomplete. For example, recent research on the microbiome highlights that microbes present in human systems (with their own unique genetic makeup) enjoy a symbiotic relationship with their hosts, participating in critical health functions such as immunity, reproduction and metabolism (Cho \& Blaser, 2012). Essentially, they are not elements of the individual per se; and just as with social ties, their loss or removal can result in important changes in individual health status.

Furthermore, social psychological research has demonstrated that close others, especially romantic partners and intimate friends, may become fused into the self in a process referred to as inclusion-of-other-in-the-self (Aron \& Aron, 1986; Aron et al., 2013). According to the self- 
expansion model (Aron \& Aron, 1986), relational partners are motivated to share resources, perspectives and even identities. Therefore, to some extent, individual's social partners become internalized and embedded within the self, and this may even be represented at a neural level (Beckes et al., 2013). Research has demonstrated that humans do not think and act untethered from social relationships, but rather carry with them mental imprints of relational partners (e.g., Chen et al., 2006; Fitzsimons \& Bargh, 2003; Shah, 2003). For example, subtly activating mental representations of relational partners has been shown to influence goal-directed behaviors consistent with those relationships (Fitzsimons \& Bargh, 2003). Given such evidence, it is easy to see how one could conceptualize a change or loss of social relationships as a change in individual social health.

\section{Multiple types of relationships experienced by the individual are important for}

social health. Another feature that appears in many conceptualizations of social health (Table 1) is a variety of forms of social relationships. In our conceptualization, each of these is potentially relevant for social health to the extent that each one is experienced at the individual level as a component of one's overall social health. Relationships with romantic partners and family are surely central to people's lives, but so too are relationships with friends, neighbors and coworkers (Reis et al., 2004). Social group memberships, broadly defined, can also serve to protect and promote health and well-being (Jetten et al., 2012). Level of intimacy or closeness is an important feature of social relationships, but is not itself a prerequisite for affecting health (Reis \& Franks, 1994), with relationships often reflected at macro-, meso- and micro-levels (Bronfenbrenner, 1979).

A strong conceptualization of social health that is capable of incorporating distinct but overlapping types of relationships (e.g., familial relationships, social group memberships) is 
essential to both unify diverse lines of work from across different disciplines (e.g., psychology, sociology, epidemiology) as well as capitalize on the theoretical and methodological expertise inherent in each of these disciplines. Working from the definition of social health offered herein, it should become clear that aspects of these various types of relationships, among others, represent constructs related to social health that might also be used as indicators of a person's overall social health if measured at the individual level.

Relevant to the individualized locus of social health, irrespective of the type of relationship examined (e.g., romantic partner, neighbor) it is possible to locate the quantity and quality of these relationships within the individual (rather than, for example, within the community or society). For example, one may live in a neighborhood with strong social ties but remain isolated and socially detached. Of course, it is likely that living in an environment with poorer social ties would predispose one toward poorer social health, just as living in a food desert predisposes one toward poorer physical health (Brown et al., 2008). In this way, the concept of social health nicely parallels physical health in terms of predisposing factors. Overall, those interested in social health should take care to consider the many types of social relationships that influence individual health and well-being.

Both the quantity and quality of relationships are important for social health. Early research on social relationships, especially social support and social integration, tended to focus exclusively on the quantitative dimension: That is, the number of social relationships to which one has access. This was partly a product of the ease with which such a dimension could be measured (e.g., asking whether one is married or single, asking how many close friends one has). However, there is growing understanding across fields that quality is just as important as quantity, if not more so (e.g., Fiori et al., 2006; Fiorillo \& Sabatini, 2011). Social relationships 
and resultant interactions can be positive and supportive, but they can also be negative and straining, leading to impaired health and well-being (Brooks \& Dunkel Schetter, 2011; Rook, 2015; Walen \& Lachman, 2000). Understanding both positive and negative aspects of social relationships (encompassed by relationship quality) is essential to linking these constructs to psychological and physical health.

Past research has demonstrated somewhat inconsistent findings regarding the benefits of sheer quantity of social relationships (e.g., Falci \& McNeely, 2009; Kim \& Lee, 2011; Liu et al., 2018; Stokes, 1983). Above a certain point, additional relationships may not bolster health and well-being, and the costs of maintaining these relationships may outweigh any potential benefits (Pescosolido \& Levy, 2002). Thus, there may be an inverted u-shaped association between quantity of social relationships and health outcomes (Liu et al., 2018). In conceptualizing social health, we use the word availability in place of quantity to denote the fact that sheer quantity alone may not be a meaningful indicator of social health. Work drawing upon the social and evolutionary function of relationships (informed by research in non-human primates as well as humans) suggests that an average social network size is approximately 150 , with humans relying on concentric social circles ever-closer in intimacy (Sutcliffe et al., 2012). According to this account, for most humans, the first two circles encompass core support networks, with these 15 or so people most helping the individual navigate the social world.

Tensions and trade-offs between network size, closeness and quality highlight the importance of considering social health more broadly, as any one operationalization may overlook intricacies of social health that can appear on balance across the multiple domains. Having just a few very close relationships of good quality with friends and family may equate to better social health than having mostly just an abundance of weaker ties of mixed quality. 
However, it is important to consider that various individual differences may play a role. For example, past work has demonstrated that women focus more on dyadic interpersonal relationships while men focus more on collective social groups (Gabriel \& Gardner, 1999). Personality characteristics such as extraversion and agreeableness, among others, may also pattern the types of relationships people seek out as well as the satisfaction and support that these types of relationships provide (e.g., Pollet et al., 2011; Swickert et al., 2002; Tov et al., 2016). It is crucial to consider that the building blocks of optimal social health may differ somewhat from person to person, but ultimately both availability and quality of social relationships are important to understanding individual social health.

\section{Both subjective and objective dimensions of social relationships are critical for}

social health. A key insight from psychological science that cuts across subdisciplines is the importance of both people's subjective perceptions and their objective experiences (Griffin \& Ross, 1991). In fact, subjective and objective measures of the same construct are often related to one another only to a limited extent (Cummins, 2000; Dang et al., 2020) and sometimes have unique effects on health and well-being outcomes, as is the case for socioeconomic status (e.g., Adler et al., 2000; Singh-Manoux et al., 2005). Sometimes, what is more important than one's social reality is the way in which that reality is framed and perceived, which is frequently a motivated process (Fiske, 1993). According to the Thomas Theorem from sociology, "If men define situations as real they are real in their consequences" (Thomas \& Thomas, 1928, p. 572).

Early work on the looking-glass self (Cooley, 1902) posited that individuals construct their self-concepts and identities through imagining how others perceive them across various social situations. In proposing the looking-glass self, Cooley concisely noted that, "The human mind is social" (p. 81). That is, humans are attuned to the social world and actively construct 
their own realities based upon their perceptions. Relatedly, self-verification theory (Swann, 1983 ) posits that people specifically prefer to socialize with others who see them as they see themselves, even when these self-views happen to be negative. Furthermore, research has shown that people are more satisfied with their relationships when they perceive their romantic partners as they would like to imagine them rather than as they actually are; that is, when they hold “positive illusions" about their partners (Murray et al., 1996a, 1996b).

Collectively, there is evidence that perceptions of social relationships, or the subjective realities in which people experience these relationships, are important to social health (Vanhalst et al., 2013). However, the actual reality of people's relationships holds importance to social health as well, offering access to jobs (Seibert et al., 2001), healthcare (Derose \& Varda, 2009) and material support in tough situations (Unger \& Powell, 1980), among other benefits. Metaanalyses indicate that markers of objective social isolation, such as living alone and having infrequent social contact, are associated with mortality in addition to perceptions of isolation (Holt-Lunstad et al., 2015, 2017). Therefore, when considering social health, it is necessary to take account of both the objective features of social relationships as well as the way in which these relationships are perceived and experienced by the individual. Having considered core features of social health, we turn to an additional critical feature for a useful conceptualization hinted at in the preceding sections, that is a dynamic framing of social health.

\section{An Allostatic Approach to Social Health}

In conceptualizing social health, we do not conceive of it as a static construct, but instead draw upon the idea of allostasis (Sterling \& Eyer, 1988) to describe its dynamic nature. Allostasis refers to "the process whereby in order to be adaptive, organisms must be able to change the defended levels of one or more regulated parameters as needed to adjust to new or 
changing environments" (Ramsay \& Woods, 2014, p. 226). As opposed to homeostasis

(Cannon, 1929), which suggests that physiological systems operate at specific set points and strive to return to those points when deviations are encountered, allostasis proposes that physiological systems engage in anticipatory regulation in response to changing circumstances, shifting set points as necessary given present and anticipated future conditions. Therefore, accurate and meaningful understanding of social health requires careful consideration of the individual and their own specific circumstances. Individual differences such as sex, culture and personality traits will influence how various indicators reflect social health differentially for one person compared to another. In addition, the relation between these indicators and social health will vary within people depending upon circumstances and environments.

Borrowing from the concept of allostasis, social health can be seen as a dynamic construct, with optimal levels that shift in response to present and anticipated future circumstances (Lee et al., 2021; Quadt et al., 2020). The same amount of social contact may become more or less adequate given other circumstances in a person's life, such as changing city or country of residence (Oishi, 2010; Watt \& Badger, 2009). Furthermore, the relative importance of the various indicators of social health discussed in the following sections may shift given changes in another one. For example, recent work shows that single people psychologically attune themselves to their friendships to a greater extent than people in romantic relationships, investing more time and effort in these friendships in order to fulfill the need for belonging (Fisher et al., 2021). Other evidence suggests that bereaved spouses may increase social engagement, for example with children or community groups, following the death of their partner (e.g., Burton et al., 2006; Utz et al., 2002). In fact, one study examining large-scale data related to communication on social-networking sites (Hobbs \& Burke, 2017) demonstrated that 
in the aftermath of the death of a friend, interactions among the remaining social network immediately increased and remained elevated for years after, making up for the decrease in interactions resulting from the absence of the deceased friend. Moreover, these increased interactions immediately after the death were more pronounced among close friends compared to acquaintances, and there was no change in interactions with strangers. This study provides strong evidence for an adaptive and naturally occurring compensation process in the domain of social health consistent with an allostatic framework.

\section{Measurement of Social Health}

Social health is a multifaceted construct that is related to a number of other widely investigated constructs, including social support, social integration/networks, loneliness, close/intimate relationships, social roles, social groups and social capital. A primary impetus for the current review is the siloed nature of these constructs within various disciplines. While strong lines of work have developed around each of these constructs, lack of a unifying social health framework has often led to redundancy in research between disciplines paired with poor resolution of both divergent and convergent findings in the overall literature. The aim of reorienting toward social health as an overarching concept is not to supplant nuanced research on the various constructs reviewed here, but rather to provide insight into how these potential facets of social health might be distinguished and to point toward ways in which these substantial bodies of research might inform and complement one another (including across disciplines).

Crucially, social health may be considered as a latent construct (Bollen, 2002; Borsboom et al., 2003; Fried, 2017). That is, although social health itself is not observable, it can be estimated from observable indicators, such as those described in the following sections. While some of the constructs reviewed here may serve as indicators of social health when assessed at 
the individual level, no single variable as operationalized or measured in past work can adequately equate to a person's overall social health. This is important because in order for health providers and health systems to begin assessing social health, they must recognize the limitations of any single indicator that they may have previously collected or be interested in collecting in the future as a representation of the multicomponent nature of social health. In the following section we provide a review of key constructs related to social health, with long traditions across various scientific fields, which might be used as indicators of social health. We begin each description with a definition of the construct, highlight some issues concerning operationalization and conclude with consideration of how the construct relates to the broader concept of social health.

\section{Constructs Related to (and Potential Indicators of) Social Health}

Social support. Perhaps the most widely investigated construct related to social health is social support. Social support has been defined previously as, "the perception or experience that one is loved and cared for by others, esteemed and valued, and part of a social network of mutual assistance and obligations" (Taylor, 2011, p. 192). Social support has been operationalized broadly (Barrera, 1986), sometimes including constructs ranging from social network size to loneliness. Researchers have distinguished between support presence (i.e., structural support) and content (i.e., functional support) as well as perceived and received support (Taylor, 2011; Turner \& Turner, 2013), distinctions that echo quantity and quality as well as subjective and objective features of social health described previously. In general, social support can be viewed as a resource that may be accessed when necessary, as in times of stress (Cassel, 1976; Cobb, 1976; Cohen \& Wills, 1985). While the vast literature on social support, and particularly its links to psychological and physical health, is important to understanding social health, defining 
social health as social support is analogous to defining physical health as physical strength. That is, social support is most often viewed as a resource that can be drawn upon in times of stress or need, just like physical strength. Furthermore, physical strength is often a product of good physical health (though not always, as in the case of someone taking steroids to attain physical strength) and social support is often available to those with good social health (though again these are not synonymous). However, social support, whether perceived or objective, should not be considered a solo proxy for social health that captures social health all by itself. Rather, social support is a product of good social health and may act as a mechanism linking social health to other health and well-being outcomes (Berkman et al., 2000).

Social integration/isolation. Social integration has been broadly defined as, "the existence or quantity of social ties or relationships, which may in turn be distinguished as to type (e.g., marital, kin/non-kin) and frequency of contact" (House, Umberson, \& Landis, 1988, p. 302). Early epidemiologic studies on social ties, such as the Alameda County (Berkman \& Syme, 1979) and Tecumseh Community Health Studies (House et al., 1982), provided compelling evidence that greater social integration is associated with reduced risk of mortality over time (House, Landis, \& Umberson, 1988). However, these studies tended to use ad-hoc approaches to measurement, combining indicators more or less relevant to social integration, ranging from visits with friends and relatives to going to classes or lectures and even listening to the radio and reading. In much subsequent work, researchers have assessed, for example, the number of people with whom one feels close enough to invite to one's home. These are relatively simplistic measures of social integration, although even these seem to have clear associations with health (Holt-Lunstad et al., 2010). More complex measures of social networks have subsequently been introduced, including features such as reciprocity, density, complexity 
and intensity (Heaney \& Israel, 2008). Indeed, these more complex measures seem to have even stronger associations with health outcomes (Holt-Lunstad et al., 2010). More sophisticated statistical methods applying social network analyses (e.g., Christakis \& Fowler, 2007) have also been introduced into the public health literature, but these techniques are more applicable to modeling population-level outcomes or the social spread of non-contagious exposures (El-Sayed et al., 2012) rather than individual health. Social integration may represent a key objective quantitative indicator of social health. However, as discussed previously, while quantity of social relationships is a facet of social health, measuring this construct in isolation cannot reveal someone's overall social health. There is certainly much to be learned about population-level social health from application of social network analyses (e.g., Cacioppo et al., 2009), but these approaches which are best suited to research on larger groups and populations must be complemented by more traditional investigations of social integration including even relatively more simplistic measures, which also allow for assessment of a variety of types of relationships.

Loneliness. Loneliness reflects the subjective feeling that one's current social relationships are of inadequate quantity or quality (Peplau \& Perlman, 1982). Although social integration (or its inverse, social isolation) and loneliness are related to one another, they are typically only modestly so, and past research has demonstrated independent effects of both of these constructs on health and well-being (e.g., Cornwell \& Waite, 2009; Coyle \& Dugan, 2012; Shankar et al., 2013). As described previously, people's perceptions of their own social realities (including their perceptions of relationships with others) are powerful determinants of health, and decades of past research have confirmed this with regards to loneliness across the life course (Hawkley \& Cacioppo, 2010; Hawkley \& Capitanio, 2015). The experience of loneliness is normative and common to most people at different points in their lives (Heinrich \& Gullone, 
2006), but sustained loneliness can be problematic. According to theory on the reaffiliation motive (Qualter et al., 2015), loneliness acts as an evolutionarily adapted signal that motivates people to seek out social connections. This is similar to the role of self-esteem proposed in sociometer theory (Leary \& Baumeister, 2000), and loneliness and self-esteem are closely related to one another in general (Mahon et al., 2006) as well as over time (Vanhalst et al., 2013), with loneliness being more relationally-focused and self-esteem more self-focused. It is clear is that humans have adapted mechanisms to gauge social inclusion and belonging for survival (Atzil et al., 2018), and therefore it is essential to query experiences of loneliness in order to fully understand social health. While social integration (or social isolation) primarily represents an objective (and quantity-oriented) indicator of social health, loneliness is decidedly a subjective indicator. Moreover, as mentioned previously, loneliness is generally considered to tap into both quality and quantity (Russell et al., 1984), further recommending it as a vital indicator of overall social health. One limitation of assessing only loneliness (in addition to its subjective rather than objective nature) is that it cannot adequately differentiate types of social relationships, nor their key features.

Close/intimate relationships. Close relationships are defined primarily by a degree of interdependence between relational partners (Kelley et al., 1983) and the fact that partners are seen as unique individuals rather than interchangeable occupants of social roles (Bradbury \& Karney, 2019). These types of relationships (e.g., with family members, friends, romantic partners) have been characterized as communal (as opposed to exchange) relationships in order to denote the special responsibilities that partners feel for one another (Clark \& Mills, 1979; Mills \& Clark, 1982). In fact, perceived partner responsiveness, or the degree to which a partner is attentive and supportive of one's self, has been proposed as an organizing construct in research 
on close relationships (Reis, 2012; Reis et al., 2004). Researchers have been studying close relationships for decades now, often in the face of false accusations of the non-scientific nature of relationship science (e.g., United States Senator William Proxmire awarded Hatfield and colleagues a "Golden Fleece Award" while claiming their research on love was "unneeded" and "frivolous"; Hatfield, 2006). Despite such opposition, the study of close relationships has flourished (Berscheid, 1999; Reis, 2007). An important contribution of research on close relationships is the identification of a number of key features, including commitment (Rusbult, 1980), satisfaction (Funk \& Rogge, 2007), passion (Hatfield \& Sprecher, 1986) and trust (Rempel et al., 1985), among others. These features are essential to understanding the quality of any given relationship (Fletcher et al., 2000). Because the number of truly close relationships is necessarily limited (Sutcliffe et al., 2012), the quality of these relationships is particularly vital to overall social health — these relationships (particularly romantic relationships) form the bedrock of most people's experiences in the social world and consequently their well-being (Diener et al., 2000; Glenn \& Weaver, 1981). However, measurement of close relationship quality is often neglected in work on social health, as these assessments are relationship-specific and social health researchers are often interested in global health and well-being. Therefore, advancing research on social health will require more nuanced investigations of the quality of close relationships, particularly those that compose the inner circle of people's social networks.

Social roles. Social roles refer to characteristic behaviors, social parts to be played and scripts for social conduct (Biddle, 1986). Different types of relationships are accompanied by distinct social roles (e.g., parent, worker, spouse, etc.), which can be further considered along with complementary roles as role-sets (e.g., parent-child, teacher-student; Merton, 1957). These social roles have sometimes been treated as proxies for social integration, but other work, 
primarily within sociology, considers the strain and enhancement that social roles may confer upon people (Wethington et al., 2000). Broadening models of life stress, it has been argued that daily strains arising from social roles may contribute to distress and impaired health (Pearlin, 1980; Pearlin \& Schooler, 1978). Social roles may at times conflict with one another, leading to even greater levels of strain for the individual (Cooke \& Rousseau, 1984). Furthermore, stress in one social role or domain may spill over into others, such as when work stress contaminates family life (Bolger et al., 1989; Schieman et al., 2009). However, roles can also enhance wellbeing through privileges, status and identity (Sieber, 1974). It is social role strain and enhancement (which are potentially related to social relationship quality) that could be most useful in assessing social health. However, researchers need to carefully identify the social elements and social relationships embedded within various roles to uncover implications for social health, rather than examining social roles as simple statuses. Alternatively, social roles may be considered as part of the social networks in which people are embedded.

Social groups. Although social groups are certainly central to social life, it can be difficult to precisely define a social group, with some proposing that at least two people "linked through interaction" comprise a social group (Biddle, 1979, p. 233). A focus on the influence of social group memberships on health has been spurred by the relatively recent introduction of the social cure model (Haslam et al., 2009, 2018; Jetten et al., 2012), which is grounded in social identity (Tajfel \& Turner, 1979) and self-categorization theories (Turner et al., 1987). This model posits that social group memberships give people control and meaning in life, fulfilling psychological needs and promoting health and well-being (Greenaway et al., 2015, 2016). In line with the definition highlighted earlier, past research has operationalized groups as anything from families (potentially just a couple) to sports clubs to national identities and beyond. These 
varied types of groups can be difficult to differentiate from their component social relationships (and social roles). Some researchers have attempted to distinguish independent associations of social relationships and social group memberships with health and well-being, sometimes arguing that social identities are even more influential than social relationships (e.g., Haslam et al., 2016; Kyprianides et al., 2019; Sani et al., 2012). Other work in this tradition has asserted that sheer quantity of social group memberships alone is predictive of health outcomes, with "the more the merrier" (e.g., Jetten et al., 2015; Jones \& Jetten, 2011). However, current evidence disentangling social groups from social relationships is limited and, in fact, some of the psychological needs fulfilled by social group memberships may be attributable to social roles within those groups (Bettencourt \& Sheldon, 2001). While social group identities are certainly critical to self-image, we argue that it is the social relationships resulting from group memberships (which may be relatively stronger or weaker as well as more or less intimate; Thoits, 2011) that are better indicators of social health. Alternatively, memberships in social groups may be viewed as another form of social integration.

Social capital. One definition of social capital is "the resources to which individuals and groups have access through their social networks" (Moore \& Kawachi, 2017, p. 213). The literature on social capital (Bourdieu, 1986; Coleman, 1988) has grown rapidly over the past few decades, primarily driven by research in public health (Carpiano, 2006; Shiell et al., 2018). More specifically, cognitive social capital refers to individual perceptions of trust, support and reciprocity (Harpham et al., 2002). There are more objective behavioral indicators of social capital, such as voting and volunteering, that are sometimes referred to as structural social capital (Rodgers et al., 2019). Social capital has also sometimes been conceptualized at a more macrosocietal level, focusing on neighborhoods and communities (e.g., Fukuyama, 2001; Putnam, 
1994). As with social support, some elements of social capital (e.g., neighborhood support) can be considered a product of good social health rather than a component. Social capital also straddles levels, primarily situated as a feature of a network or group, but accessible to the individual. However, the concept of social capital is also useful in drawing attention to types of social relationships (e.g., neighbors, fellow church members) that are often overlooked in research on other social health-related constructs that may need to be accounted for when querying overall social health. It is clear from past research that social capital influences health and well-being, although effects can be both positive and negative (Ehsan et al., 2019; Rodgers et al., 2019), echoing the importance of examining quality rather than just quantity in social health. Most importantly, those interested in using social capital as an indicator of social health should focus on individual perceptions/behaviors.

From the breadth of constructs and disciplines represented in our review, it is clear that constructs related to (and potential indicators of) social health have been extensively studied, although rarely considered under the umbrella of the broader framework of social health that we propose. While researchers should continue to investigate these distinct constructs, using the best tools and theories available from within and across disciplines, a unifying framework will help the scientific study of social health to flourish. Echoing the famous Indian folk tale of "The Blind Men and the Elephant," in which a group of blind men try to describe an elephant by touching separate parts and inaccurately characterizing the creature according to the limited section of the animal that they happened to come across, our goal is to help researchers uncover the underlying construct of social health rather than describing each individual part that they happen to investigate as a unique and wholly independent entity. A vital next step in 
understanding social health is to tackle the daunting task of operationalizing what is clearly both a dynamic and multifaceted construct.

\section{Operationalizing Social Health}

A comprehensive review of measures or scales relevant to social health is beyond the scope of this work, and readers are encouraged to reference other thorough reviews in order to assess potential options (e.g., Bowling, 2004; Donald et al., 1978; Valtorta et al., 2016).

However, one of the primary obstacles to adopting social health as a component of overall health and well-being has involved ambiguities and inconsistencies in the operationalization of this construct. Therefore, it is essential for researchers to more rigorously explore and develop comprehensive measures of overall individual social health (Waite, 2018).

Relevant work has been undertaken as part of the Patient-Reported Outcomes Measurement Information System (PROMIS) initiated by the United States National Institutes of Health (NIH) in 2004. Initial item pools were developed and structured around the WHO definition of health (Cella et al., 2007). A PROMIS Social Health Workgroup conducted qualitative focus group analyses and subsequently psychometric assessments on a novel measure of social health (Castel et al., 2008; Hahn et al., 2010). In these studies, social health encompassed social function (including ability to participate and satisfaction with participation) and social relationships (including social isolation as well as quality and quantity of social support), yet the final measure developed by this group did not include all subdimensions of social health as some elements of the measure did not evidence adequate psychometric properties (Hahn et al., 2010). Separately, the United States Institute of Medicine (IOM) convened an expert committee to improve the quality of psychosocial and behavioral data collected in electronic health records. In the interest of brevity, the committee recommended the use of a 
four-item measure of social integration (Berkman \& Syme, 1979; Pantell et al., 2013) to assess social relationships in electronic health records in the United States (Matthews et al., 2016), although the committee also recommended further consideration of measures of social support and loneliness in the future (IOM, 2014).

These initial efforts are encouraging, yet because social health is multifaceted (as are psychological and physical health), it is impractical to expect one measure (or one indicator) to accurately and fully gauge this construct. We suggest that a latent factor approach may be able to more effectively gauge and classify levels of social health. Based upon our review of potentially relevant indicators, we recommend that a thorough assessment of social health should include, at minimum, measures of social integration, loneliness, close relationship quality and social capital (in the form of individual perceptions of relationships with communities and social groups, for example). Notably, some of these indicators may overlap in the content they cover depending upon operationalizations or specific components of scales to be used. However, including some combination of these and other indicators measured at the individual level will allow for a more comprehensive understanding of social health that should assist in efforts to improve overall human health and well-being, including preventing morbidity and mortality. These suggestions are based upon our theoretical and conceptual review of the construct of social health, but we strongly recommend that future psychometric work be conducted to test associations between these indicators and the proposed underlying latent factor, as well as its suitability for inclusion in research, practice and policy. Measurement issues related to social health remain an especially fertile ground for further investigation. Disconnection between individual experience and the broader social context may hinder assessment to some extent, and weaker correlations between individual indicators may be expected given the dynamic nature of 
our conceptualization (with the importance of certain indicators shifting given changes in others as well as changes in the social environment). Yet given the centrality of measurement to the success of scientific endeavors (Flake \& Fried, 2020), it is critical to persist in these efforts in order to identify what might be considered a relatively difficult-to-access construct.

In addition, researchers should continue to examine unique components of social health independently, but with greater clarity regarding the specific components in which they are interested. Researchers should be encouraged to situate their work within the broader framework of social health in order to speak fluently across research programs and disciplines and allow a larger literature on social health to flourish while still maintaining the focus on each of the unique constructs reviewed in the previous section. Once again, it is not our intention for social health to supplant each of these established lines of work, but rather to allow for an overarching framework of social health research in order to advance human health and well-being.

\section{Connecting Physical, Psychological and Social Health: A Tripartite Model}

Drawing upon the WHO's definition of health, social health is here positioned as one of three interconnected components, along with physical and psychological health. This type of overlapping model of health (displayed in Figure 1) is timely given increasing recognition of the importance of social relationships to public health (e.g., Holt-Lunstad et al., 2017) and echoes other recent proposals in the literature (e.g., Haslam et al., 2019; Karunamuni et al., 2020). Crucially, we do not assume that any one of these three components are more important or primary to health and well-being than any of the others, as some past models have suggested (Suls et al., 2010). Rather, these three components are inextricably bound and mutually influential. Therefore, the central aim of this paper is to propose a tripartite model of health, 
placing social health equally and indivisibly alongside the other two components in health theory, research and practice.

There is already extensive evidence that social relationships influence physical and mental health outcomes across the life course (in addition to mortality). Many decades of research (e.g., see Leigh-Hunt et al., 2017 for an overview of systematic reviews) have linked poor social health to onset and progression of physical health disorders (e.g., cardiovascular disease [CVD], cancer, chronic obstructive pulmonary disease) as well as mental health disorders (e.g., depression, anxiety, dementia). Dominant models linking social relationships and health (e.g., Berkman et al., 2000; Hawkley \& Cacioppo, 2010; Pietromonaco \& Collins, 2017; Robles et al., 2014) make strong arguments for the importance of social relationships in shaping human health and well-being. However, in each of these models, social health is positioned as a predictor of psychological and physical health outcomes, overlooking its potential role as a dependent variable. The starkest example of this consistent theoretical placement is from work on social support (the most widely investigated construct related to social relationships and health), which has been extensively discussed in terms of a main effect versus buffering model (i.e., positioning social factors as either an independent variable or moderator of the effects of stress on health; Cohen \& Wills, 1985). However, social health is decidedly more intertwined with these other components than such unidirectional models presume (Diez Roux, 2007).

In addition to some of the conditions already described, an example that compellingly illustrates this intertwined nature of health is the nexus of depression, social disruption and CVD (indicators of psychological, social and physical health respectively). Researchers have identified bidirectional effects between each of these conditions - social disruption and depression (Davila et al., 1997; Whisman \& Uebelacker, 2009), depression and CVD (e.g., 
Mosovich et al., 2008; Whooley \& Wong, 2013) and CVD and social disruption (e.g., Daniel et al., 2009; Havranek et al., 2015). Complicating matters further, chronic inflammation may be a common mechanism linking social disruption and depression, with synergistic effects among these outcomes (e.g., Jaremka et al., 2013; Kiecolt-Glaser et al., 1987). In turn, this proinflammatory state that appears to be a signature of depression is also highly implicated in CVD risk (Libby, 2006). Proinflammatory cytokines have further been causally linked to social withdrawal (i.e., "sickness behaviors") in non-human animals (Dantzer et al., 2008) as well as humans (e.g., Eisenberger et al., 2010; Inagaki et al., 2012). Taken together, evidence suggests a common underlying chronic inflammatory state in comorbid stress-related cardiovascular, depressive and psychosocial illnesses (Finnell \& Wood, 2016; Furman et al., 2019; Slavich \& Irwin, 2014), perhaps serving an evolutionarily protective function against physical and social threats (Slavich, 2020).

Another example of the intertwining of these three components relates to the opioid crisis and bidirectional links between substance use disorders, social isolation and chronic pain (once again, indicators of psychological, social and physical health respectively). People are often initially prescribed opioids for the management of chronic pain (including pain resulting from cancer as well as other physical health conditions), but psychological (and physical) dependence can develop and lead to substance abuse and addiction over time. Importantly, a recent systematic review (Cance et al., 2021) found strong support for a link between social isolation and opioid misuse. While there is evidence that substance use disorders can lead to increased social isolation, for example, through rejection by families and social networks, social isolation and consequent loneliness can also drive the onset of substance use disorders as well as recovery trajectories (Ingram et al., 2020), including for opioid addiction (Jeste et al., 2020). Loneliness 
increases daily perceptions of pain concurrently and over time (e.g., Jaremka et al., 2014; Wolf \& Davis, 2014), but chronic pain can also lead to increased social isolation and loneliness (e.g., Emerson et al., 2018); in fact, social and physical pain may share neural signatures (Eisenberger et al., 2003). The particular example of opioid addiction is potentially even more intriguing in that some researchers have proposed endogenous opioids as a key biological mechanism driving social bonding and connection, referred to as the brain opioid theory of social attachment (Inagaki, 2018; Machin \& Dunbar, 2011). This theory supports a common biological (and motivational) pathway underlying pain, addiction and social connection (Inagaki, 2018).

What these complex examples illustrate is the intertwined and potentially inextricable nature of the three components of health outlined in the tripartite model (as well as their inherently biological embeddedness). Numerous reviews (e.g., Berkman, 1995; House, Umberson, \& Landis, 1988; Taylor, 2011; Uchino et al., 2012) have called for a concerted search for biological mechanisms linking social relationships to physical (and sometimes psychological) health. While admirable in aiming to connect these three components of health, this search for unidirectional candidate mechanisms, from social relationships to health, is somewhat misguided given the framework for social health presented here (however, see Karunamuni et al., 2020 for a review focused on explicating causal associations in multiple directions between various combinations of each of these three components of health).

\section{The Human Body (and Mind) as the Locus of (Social) Health}

Under the tripartite model of health, the human body is host to each of the three components (physical, psychological, social; see Figure 1). Dualism, as opposed to monism, is the belief that the mind (or spirit) is "immaterial" and has no corporeal form; that is, it is distinct from one's physical body. Although few researchers in the social or health sciences today 
endorse the notion of a discrete separation between mind and body (Damasio, 1994), this perspective pervaded Western thought for much of the past four centuries. In our model, we assert that all elements of health are encoded in the human body (and brain), including social elements. This is not as radical a proposal as it may seem upon first glance, and in fact, decades of research have demonstrated that social stimuli are processed and experienced via biological systems and that these same systems, in turn, shape social emotions, cognitions and behaviors (Cacioppo et al., 2000, 2015; Cozolino, 2014; Feldman, 2017; Hoffman et al., 2014; Schulkin, 2011). The social nature of human biological systems is so evolutionarily ingrained that researchers have proposed the idea of a social brain (Atzil et al., 2018; Dunbar, 1998; Insel \& Fernald, 2004; Porcelli et al., 2019).

There is now mounting evidence for core biological systems involved in social processes and social relationships. At the neuroendocrine level, the oxytocinergic system is critical in social bonding and other social cognitive processes in humans as well as non-human animals (Carter, 1998; Bartz et al., 2011; Insel, 2010). Oxytocin, along with vasopressin, prolactin and endogenous opioids, are vital in establishing the first social bond between parent and child (Carter, 1998; Feldman \& Bakermans-Kranenburg, 2017). Consistent with attachment theory, the oxytocinergic system is later stimulated in warm touch and affection between adult romantic partners (Holt-Lunstad et al., 2008) and tracks closely to relational commitment and stability (Schneiderman et al., 2012; Van Anders et al., 2011). Furthermore, this system seems to be involved in shaping the ability of social support to soothe the biological stress response (e.g., buffering the hypothalamic-pituitary-adrenal axis; Hostinar et al., 2014). Beyond its role in close relationships, the oxytocinergic system also appears to pattern intergroup behavior and processes to some extent (De Dreu, 2012). Oxytocin may even be central to the experience of social 
isolation and loneliness (Carter, 2014). Functioning of the oxytocinergic system is patterned in part by genetic variations (e.g., in the oxytocin-receptor gene), which are further subject to epigenetic regulation by social experiences (Kumsta et al., 2013), all of which influences social functioning (Maud et al., 2018). It is worth noting that there is currently ongoing controversy over methods for the measurement and manipulation of oxytocin in humans (e.g., MacLean et al., 2019; Quintana et al., 2018), which may limit some of the cohesiveness of research in this area and leaves room for further elaboration of the role of the oxytocinergic system in human social relationships.

At the neural level, some researchers have proposed that overlapping brain regions are responsible for processing both physical and social pain (Eisenberger et al., 2003). Similarly, experiencing pain oneself may share activation of neural regions with empathic responses to others' pain (Singer et al., 2004). While the exact interpretation of this regional overlap is currently being debated (e.g., Lamm \& Majdandžić, 2015; Wager et al., 2016), there is evidence that social relationships are deeply embedded in neural systems. Notably, the amygdala, dorsal anterior cingulate cortex, periaqueductal gray and anterior insula appear to be most involved in social threats and disconnection, while the ventromedial prefrontal cortex, ventral striatum and septal area appear to be most involved in social support and connection (Eisenberger \& Cole, 2012). In particular, converging lines of research suggest a central role for the amygdala network in anchoring social functioning (Bickart et al., 2014). Importantly, all of these neural regions interact with other biological systems (neuroendocrine, autonomic and immune) in the regulation of and response to social stimuli in humans.

Another line of evidence for the embodiment of social relationships comes from work on biobehavioral synchrony between relational partners (Feldman, 2017; Timmons et al., 2015). At 
the behavioral level, some research demonstrates that people engage in nonconscious mimicry of social interaction partners, which can facilitate liking (Chartrand \& Bargh, 1999). Behavioral synchrony may be once again shaped by early parent-child interactions (Feldman, 2007) and carry over into adult close relationships (Ulmer-Yaniv et al., 2016). Beyond the behavioral level, research with romantic couples demonstrates a degree of synchrony across biomarkers, such as oxytocin (e.g., Ulmer-Yaniv et al., 2016), heart rate (e.g., Helm et al., 2012) and respiratory sinus arrhythmia (e.g., Helm et al., 2014). These linkages once more reflect the extent to which social relationships are intertwined with individual (and dyadic) biology. Increasingly, scientists are beginning to recognize that human biology is incredibly sensitive (in both a reactive and anticipatory fashion) not only to the external (e.g., Schulkin, 2011) but also to the internal social milieu (e.g., Picard \& Sandi, 2021).

In some ways the term biopsychosocial is misleading, as all health is intimately bound to our biology. Perhaps physiopsychosocial would be a more useful term in that it more clearly differentiates the physical health component from human biology. Critics have indeed pointed out that despite its rejection of dualism, the biopsychosocial model, as proposed by Engel and advocated by others, falls prey to dualism by treating biology as concretely separate from psychosocial factors (Ghaemi, 2011). Instead, we suggest a tripartite model of health, as this label obviates the need to choose an order of placement for each component, which may subtly signal primacy (Haslam et al., 2019). Rather, human health is viewed as a product of each of these three components, situated within the human body (and mind; see Figure 1).

\section{Social Health in the Population}

Perhaps no other event in modern history has laid bare the importance of understanding social health quite like the COVID-19 pandemic. As a result of the aggressive spread of this 
communicable virus, governments and health authorities across the world have needed to balance measures aimed at protecting physical health with potential consequences for mental and social health. While some nations and states have attended to all three forms of health more explicitly than others, there have been serious concerns about unintended consequences for mental and social health on a global scale (e.g., Aleman \& Sommer, 2020; Bzdok \& Dunbar, 2020; Galea et al., 2020; Holt-Lunstad, 2021). One of the most aggressive measures, full-scale national lockdown, has the potential undesired effect of creating social isolation, particularly for the most vulnerable groups in society (Campbell, 2020; Gauthier et al., 2020). Even less aggressive measures, including physical distancing (sometimes referred to as "social distancing"), may strain social health (e.g., Ford, 2020; Heid et al., 2021; Heidinger \& Richter, 2020; Kovacs et al., 2021; Krendl \& Perry, 2021; Lee et al., 2020; van Tilburg et al., 2020). Some in popular media have warned of a looming mental and social health crisis in the months and years following recovery from the pandemic (e.g., Delaney, 2020; Stern, 2020; Wallis, 2021). It is worth noting that other preliminary evidence (e.g., Folk et al., 2020; Luchetti et al., 2020; Williamson, 2020) suggests null or mixed effects of physical distancing on various indicators of social health in the immediate aftermath of the pandemic. Whether this stability in social health is short-lived or is found in other research in the long-term remains to be seen, but what is clear is that only through acknowledging the tripartite model of health presented here can researchers, clinicians and policy makers begin to understand the complicated balancing of concerns for physical, mental and social health in the population in response to the COVID-19 pandemic.

\section{Enabling Social Health in Populations}


Societies can enable (or inhibit) social health through health systems, public policies and social norms that promote (or hinder) cultures and environments allowing for the flourishing of healthy social relationships (Hinchliffe et al., 2018). One example of a holistic approach that has potential to enable social health and increase longevity comes from research on "blue zones" (Buettner \& Skemp, 2016; Poulain et al., 2013). Blue zones are geographic regions around the world with the highest proportion of centenarians (e.g., the Nicoya peninsula in Costa Rica, the Okinawa islands in Japan). It has been noted that these regions share health-promoting features that incorporate factors related to physical, psychological and social health. For example, in addition to culturally-embedded stress reduction techniques (e.g., prayers, napping) and healthy diets (e.g., plant-based diets and moderate alcohol consumption), these regions are characterized by a strong sense of belonging and close social ties (e.g., frequent social interactions, faith-based community participation; Buettner \& Skemp, 2016). In Okinawa, people use the phrase yuimaru to refer to a "spirit of mutual aid and sense of trust and reciprocity" in the community (Shirai, 2020, p. 305). While public health and policy attempts to artificially recreate such zones in other parts of the world have been justifiably critiqued for engaging in "libertarian paternalism," potentially seeking to "nudge" behavior rather than form healthy cultures and environments (Carter, 2015), it is still valuable to consider how these societies that are successful in enabling longevity tend to prioritize social alongside physical and psychological well-being.

In several countries around the world, governments and communities are beginning to consider various approaches to enabling social health. For example, cohousing (originally developed in Denmark, Sweden and the Netherlands; Sargisson, 2012), in which residents occupy private dwellings alongside communal areas and shared spaces managed by the community, may potentially benefit social health (although there is currently only limited 
evidence from typically low-quality studies to support causal effects on these outcomes; Warner et al., 2020). Within the United Kingdom, social prescribing has recently been developed as part of a holistic approach to healthcare that is person-centered and can help to address social determinants of health, including loneliness and social isolation (Kellezi et al., 2019). Social prescribing aims to link primary healthcare services to community and voluntary sector organizations, such as befriending groups, bereavement groups and volunteering organizations (South et al., 2008). As with cohousing, evidence suggests beneficial effects but comes primarily from a limited number of low-quality studies (Bickerdike et al., 2016; Reinhardt et al., 2020).

Much of the evidence-base for interventions aimed at improving individual social health comes from research on trials targeting loneliness. Meta-analyses of diverse loneliness interventions among adults (Masi et al., 2011) as well as youth (Eccles \& Qualter, 2021) reveal consistent and moderate average effect sizes across reviews, with high variability in effect sizes between interventions. Similarly, systematic reviews of loneliness interventions among older adults (e.g., Gardiner et al., 2018; Poscia et al., 2018) tend to support positive effects, although noting the weakness of the quality of evidence in general. Limited evidence also hints at the ability of various interventions to increase social capital (Flores et al., 2018), social support (Hogan et al., 2002), and social group identification (e.g., Steffens et al., 2019). Perhaps the longest history of intervention in social health comes from work in the domains of marital and family therapy. A recent review of the literature on various clinical interventions for couples (Bradbury \& Bodenmann, 2020) concluded that most are effective in reducing distress and increasing satisfaction and stability, with effects sometimes enduring after couples have exited therapy. Moreover, many preventative interventions for couples also show evidence of 
preventing relationship distress, albeit to a weaker extent (Bradbury \& Bodenmann, 2020). What most of these systematic reviews share in common is that they highlight the limited efforts that have been made to carefully and precisely evaluate interventions targeting social health — a key direction for future research.

Generally, the interventions that have been tested (or evaluated through clinical trials) focus on improving social health for those already experiencing poor social health or those who are most at risk of experiencing poor social health in the future. A different approach that has not received much attention, despite some calls within the scientific literature (e.g., HoltLunstad, 2018), is to attempt to implement a minor shift of the social health curve at the population level rather than focusing exclusively on at-risk individuals (Rose, 1985). This is more consistent with the blue zones approach or potentially cohousing models, which have been increasing in popularity in various countries (Krokfors, 2014), but other novel population-based interventions targeting social health could be developed on a larger scale. In addition to considering interventions aimed at enabling social health, it is crucial that health systems begin to monitor social health in the population (Hashemi et al., 2016; Holt-Lunstad et al., 2017) in addition to psychological and physical health. Assessments of social health should be performed in routine healthcare and measures of social health should be embedded in population-based surveys. Only through careful monitoring of population-level social health can governments and societies ensure the overall well-being of their people. As highlighted previously, enabling social health has social and economic benefits for societies (Mihalopoulos et al., 2020), but it should ultimately be motivated by the goal of ensuring human rights (Sen, 2008; Susser, 1993).

\section{Disparities in Social Health}


An ever more pressing reason for researchers to swiftly reconsider the notion of social health in the population (as well as how best to monitory it) is the accumulating literature suggesting that this construct may be socially patterned in vital ways. Across diverse demographic characteristics, including but not limited to race, sex, age, sexual orientation, and socioeconomic status, differences in social health are becoming increasingly apparent (Waite, 2018). A striking pattern that has caught the attention of prior scholars (e.g., Doyle et al., 2018; Doyle \& Molix, 2014b; Hatzenbuehler et al., 2013; Umberson \& Montez, 2010) is that members of stigmatized or devalued groups tend to evidence poorer social health relative to members of dominant groups. That is, as with entrenched psychological and physical health disparities (Adler \& Rehkopf, 2008; Braveman et al., 2011; Hatzenbuehler et al., 2013), there is strong and growing evidence for disparities in social health.

For example, sexual minorities tend to experience poorer social health relative to heterosexuals, including elevated levels of loneliness and close relationship strain as well as lower levels of social capital (Doyle \& Molix, 2016). Sexual minority youth experience high levels of bullying and social rejection (e.g., Olsen et al., 2014; Poteat et al., 2020), including sometimes from their own families (McGeough \& Sterzing, 2018). There is also some evidence for greater instability in same-sex romantic relationships compared to different-sex relationships (Manning \& Joyner, 2018). Together, these disparities in social health may help explain elevated levels of suicide risk among sexual minority youth and adults (Plöderl et al., 2014; Poštuvan et al., 2019). Racial and ethnic minorities also tend to experience poorer social health relative to Whites. For example, African American men and women are less likely to marry and more likely to divorce than White men and women (Raley et al., 2015) and report lower marital quality on average (Bulanda \& Brown, 2007). Racial and ethnic minorities tend to have lower 
social capital (Lin, 2000) and some evidence hints at smaller social networks compared to Whites (e.g., Ajrouch et al., 2004; Miyawaki, 2015). Other research indicates that racial and ethnic minorities are also at greater risk of experiencing loneliness compared to Whites, particularly in older age (e.g., Hawkley et al., 2008; Miyawaki, 2015; Tomaka et al., 2006; Victor et al., 2012).

As with other inequalities, the COVID-19 pandemic is not only bringing these disparities in social health to light, but it may also be exacerbating them (Campbell, 2020; Gauthier et al., 2021). Increased burdens of structural stressors (e.g., decreased financial stability; Bui et al., 2020) may further strain social relationships for members of devalued groups. Moreover, the inequalities in morbidity and mortality from COVID-19 (Bambra et al., 2020; Van Dorn et al., 2020) will lead to greater disruption and loss in social networks. Taken together, the toll of the COVID-19 pandemic on social health is likely to be more severe for members of stigmatized and devalued groups.

In chronicling these disparities in social health, it is important to stress that the evidence does not support an essentialist perspective in which members of stigmatized groups are inherently less capable of maintaining healthy and satisfying social relationships. Rather, there are myriad cultural and structural factors that work to impair social health for members of devalued groups across societies. Perhaps chief among these is exposure to prejudice and discrimination. There is now growing evidence from research with a variety of stigmatized groups (including sexual and racial minorities) that exposure to prejudice and discrimination damages social health (e.g., Chen \& Yang, 2014; Doyle \& Molix, 2015; Murry et al., 2001; Priest et al., 2017; Trail et al., 2012), potentially through mechanisms such as impaired selfimage (Doyle \& Molix, 2014a) and emotion dysregulation (Doyle \& Molix, 2014c). 
Furthermore, experimental evidence demonstrates that exposure to prejudice and discrimination causally inhibits trust (Zhang et al., 2020), impairs close relationship quality (Doyle \& Molix, 2014b), increases loneliness (Doyle \& Barreto, 2021) and decreases sensitivity to signals of social inclusion (Richman et al., 2016). In one study (Doyle \& Molix, 2016), perceived discrimination was shown to explain much of the gap in social health between sexual minorities and heterosexuals.

Of course, as with any outcome of interest, there are protective factors and sources of resilience for social health unique to various stigmatized groups. For example, sexual minorities often form strong bonds with "families of choice" because of frequent experiences of rejection from "families of origin" (Frost et al., 2016). Among many racial and ethnic minority groups, it is also common to form "extended families" that encompass both actual and "fictive" kin, particularly to provide support in raising children (Ebaugh \& Curry, 2000; Harrison et al., 1990). More broadly, there is work to suggest that in response to discrimination and rejection from members of dominant groups, members of stigmatized groups may draw closer to other in-group members as a source of support and affirmation (i.e., the rejection-identification model; Branscombe et al., 1999). However, acknowledging these sources of protection and resilience does not obviate substantial disparities in social health that appear to be patterned across a number of different devalued social identities.

Turning back to the tripartite model of health, disparities in social health between devalued and dominant groups may help explain the development and maintenance of disparities in other forms of health across the life course (i.e., physical and psychological; Doyle et al., 2018). "Beneficial social connections" have been deemed a key flexible resource that facilitates the recreation of health inequalities in different places and time (Phelan et al., 2010). In fact, 
social health may represent a pathway through which "fundamental causes" (Link \& Phelan, 1995), including social stigma (Hatzenbuehler et al., 2013), shape other health outcomes. Therefore, efforts to eliminate disparities in social health may have the added benefit of effectively reducing other entrenched health inequalities as well. As with physical and psychological health, we have demonstrated that there are important disparities in social health that must be attended to by future researchers.

\section{Social Health over Time and across Generations}

Research demonstrates that social health also fluctuates throughout the individual life course (Mund et al., 2020; Blieszner, 2006; Ertel et al., 2009; Luong et al., 2011; Wrzus et al., 2013), just as physical and psychological health do (Ben-Shlomo \& Kuh, 2002). As with other forms of health, there is growing evidence that social health is patterned from early life through adulthood and into older age (Doyle \& Cicchetti, 2017; Simpson et al., 2011; Umberson et al., 2016). Attachment theory (Bowlby, 1973) proposes that the presence of caring and responsive relational partners (serving as a "secure base") allows one to explore the social environment and cope with novel and potentially threatening social stimuli in a healthy manner. Although attachment theory was originally developed with reference to the parent-child relational bond (Ainsworth et al., 1978; Bowlby, 1973), the theory was subsequently expanded to include adult relational partners (Hazan \& Shaver, 1994). Attachment patterns are thought to form early on and persist throughout development (Fearon \& Roisman, 2017; Fraley, 2002), but have also been shown to be capable of change from one relational partner to another (e.g., La Guardia et al., 2000). Of note, social health is intimately bound not only to life expectancy, as reviewed previously, but also to life chances. Just as with physical and psychological health, social health patterns so much about a person's life trajectory, including educational attainment (e.g., Dufur, 
Parcel, \& Troutman, 2013), career prospects (e.g., Seibert et al., 2001), residential independence (e.g., Seiffe-Krenke, 2006) and family formation (e.g., Thorsen, 2017).

In addition to patterning throughout the individual life course, there is some evidence for shifts in indicators of social health across generations (which are mirrored by shifts in predominant physical illnesses, as described previously, as well as increasing prevalence of certain mental health conditions over time, such as autism spectrum disorder; Myers et al., 2019). For example, it has been argued that social capital is decreasing on average over time in the United States (Putnam, 2000). Examples of this decline include shrinking membership in community groups and voluntary organizations, less time spent on informal visiting and socializing, and decreasing church attendance (Putnam, 1995). Other work has demonstrated a reduction in the size of average American discussion networks, including with kin and non-kin, between 1985 and 2004 (McPherson et al., 2006). A recent meta-analysis also showed evidence for a lower prioritization of values of affiliation and community across generations in the United States (Twenge \& Campbell, 2012). On a more global scale, there has been a dramatic rise in the number of people living alone, particularly since the 1960's (Snell, 2017). This shift in living patterns corresponds to rising reports of loneliness, which have been substantial enough to lead some academics as well as mass media to label this phenomenon a "loneliness epidemic" (e.g., Bergland, 2015; Holt-Lunstad, 2017; Murthy, 2017).

Despite such seemingly dramatic changes in human health and well-being over time, some of these patterns have been empirically challenged or reinterpreted through the lens of shifting social norms around individualism and independence as well as the rise of technology and social media (e.g., Bound Alberti, 2018; Hampton \& Wellman, 2018; Klinenberg, 2018; Suanet \& van Tilburg, 2019). Undoubtedly, technology is shaping ways in which social 
relationships are mediated in the current era (Bayer et al., 2020; Kross et al., 2021), which could have implications for social health on a broad scale. More than ever before, the COVID-19 pandemic has transformed people's social lives, increasing time spent socializing via digital technology and on-line services (Ohme et al., 2020). Furthermore, some researchers are currently investigating "social robots" as a solution to poor social health, particularly among older adults (Broekens et al., 2009; Pu et al., 2019). It is unclear to what extent such technological interventions will be capable of bolstering social health, with limited and generally low-quality evidence available at present (Noone et al., 2020; Pu et al., 2019). Additionally, there are ethical issues inherent in the "humanization" of social robots (Giger et al., 2019). However, this remains an area of financial investment and a research priority for many societies concerned with the possibility of flagging levels of social health in the population. Shifting patterns of social health across time within individuals as well as between generations (just as with physical and psychological health) necessitate a life course perspective utilizing a historical lens to best capture the construct of social health.

\section{Conclusion}

Building upon our intuitive understanding of the construct along with extensive theorizing of others who came before us, we set out to explicitly conceptualize the phenomenon of social health. To begin, we situated the construct of social health within an ever-evolving and lengthy history of conceptualizations of health and well-being across societies. Next, we offered our own definition of social health based upon a review of prior literature (Table 1), describing how it 1) is conceptualized at the individual level, 2) involves multiple types of social relationships experienced by the individual, 3) reflects both the quantity and quality of social relationships and 4) includes subjective and objective dimensions. To further highlight the 
dynamic and multifaceted nature of our conceptualization of social health, we borrowed from theory on allostasis to describe the malleable nature of its components and referred to psychometric work on latent constructs to potentially best capture its structure. We included a review of constructs related to social health, with long traditions across various scientific fields, which might be used as indicators of social health — specifically drawing attention to the potential utility of measures of social integration, loneliness, close relationship quality and social capital.

Turning to the importance of social health, we began by documenting the exceptionally strong evidence base linking facets of social health to morbidity, mortality and health-related quality of life. We discussed costs associated with poor social health and the burden on society. Our discussion of social patterning highlighted a number of ways in which demographic characteristics, including age and generational cohort, might influence social health. In particular, we sought to draw attention to pronounced disparities in social health between members of stigmatized and dominant groups that echo entrenched disparities in physical and psychological health.

Finally, we underscored the utility of our conceptualization of social health by illustrating the intertwined nature of physical, psychological and social health, proposing a tripartite model (Figure 1). We demonstrated how this model links these three components of health through the human body (and mind), with implications for understanding and addressing the health-related causes and consequences of recent major world events, ranging from the opioid crisis to the COVID-19 pandemic, as well as emerging and prominent conditions at the individual level, such as hikikomori and chronic severe loneliness. Through strategies that enable social health across populations and cultures, such as blue zones, cohousing and social prescribing, it may be 
possible to improve other domains of health (i.e., physical and psychological) and ensure a state of optimal human functioning for all. For these reasons, we assert that it is time for scholars across the social sciences and health disciplines to unabashedly embrace the pursuit of social health. 


\section{References}

Adler, N. E., Epel, E. S., Castellazzo, G., \& Ickovics, J. R. (2000). Relationship of subjective and objective social status with psychological and physiological functioning: Preliminary data in healthy, White women. Health Psychology, 19(6), 586-592. https://doi.org/10.1037/0278-6133.19.6.586

Adler, N. E., \& Rehkopf, D. H. (2008). US disparities in health: Descriptions, causes, and mechanisms. Annual Review of Public Health, 29, 235-252.

https://doi.org/10.1146/annurev.publhealth.29.020907.090852

Ainsworth, M. D. S., Blehar, M. C., Waters, E., \& Wall, S. (1978). Patterns of attachment. Hillsdale, NJ: Lawrence Erlbaum.

Ajrouch, K. J., Antonucci, T. C., \& Janevic, M. R. (2001). Social networks among blacks and whites: The interaction between race and age. The Journals of Gerontology Series B: Psychological Sciences and Social Sciences, 56(2), S112-S118. https://doi.org/10.1093/geronb/56.2.S112

Akashi, Y. J., Goldstein, D. S., Barbaro, G., \& Ueyama, T. (2008). Takotsubo cardiomyopathy: A new form of acute, reversible heart failure. Circulation, 118(25), 2754-2762. https://doi.org/10.1161/CIRCULATIONAHA.108.767012

Aleman, A., \& Sommer, I. (2020). The silent danger of social distancing. Psychological Medicine, 1-2. https://doi.org/10.1017/S0033291720002597

Alonso, Y. (2004). The biopsychosocial model in medical research: The evolution of the health concept over the last two decades. Patient Education and Counseling, 53(2), 239-244. https://doi.org/10.1016/S0738-3991(03)00146-0 
Aron, A., \& Aron, E. N. (1986). Love and the expansion of self: Understanding attraction and satisfaction. Washington, DC: Hemisphere Publishing Corporation.

Aron, A., Lewandowski, G. W., Mashek, D., \& Aron, E. N. (2013). The self-expansion model of motivation and cognition in close relationships. In J. A. Simpson \& L. Campbell (Eds.), The Oxford handbook of close relationships (pp. 90-115). Oxford, UK: Oxford University Press.

Atzil, S., Gao, W., Fradkin, I., \& Barrett, L. F. (2018). Growing a social brain. Nature Human Behaviour, 2(9), 624-636. https://doi.org/10.1038/s41562-018-0384-6

Bambra, C., Riordan, R., Ford, J., \& Matthews, F. (2020). The COVID-19 pandemic and health inequalities. Journal of Epidemiology and Community Health, 74(11), 964-968. https://doi.org/10.1136/jech-2020-214401

Barrera Jr, M. (1986). Distinctions between social support concepts, measures, and models. American Journal of Community Psychology, 14(4), 413-445. https://doi.org/10.1007/BF00922627

Barnes, L. L., Mendes de Leon, C. F., Bienias, J. L., \& Evans, D. A. (2004). A longitudinal study of Black-White differences in social resources. The Journals of Gerontology Series B: Psychological Sciences and Social Sciences, 59(3), S146-S153. https://doi.org/10.1093/geronb/59.3.S146

Bartz, J. A., Zaki, J., Bolger, N., \& Ochsner, K. N. (2011). Social effects of oxytocin in humans: Context and person matter. Trends in Cognitive Sciences, 15(7), 301-309. https://doi.org/10.1016/j.tics.2011.05.002 
Baumeister, R. F., \& Leary, M. R. (1995). The need to belong: Desire for interpersonal attachments as a fundamental human motivation. Psychological Bulletin, 117(3), 497-529. https://doi.org/10.1037/0033-2909.117.3.497

Bayer, J. B., Triệu, P., \& Ellison, N. B. (2020). Social media elements, ecologies, and effects. Annual Review of Psychology, 71, 471-497. https://doi.org/10.1146/annurev-psych$\underline{010419-050944}$

Beckes, L., Coan, J. A., \& Hasselmo, K. (2013). Familiarity promotes the blurring of self and other in the neural representation of threat. Social Cognitive and Affective Neuroscience, 8(6), 670-677. https://doi.org/10.1093/scan/nss046

Ben-Shlomo, Y., \& Kuh, D. (2002). A life course approach to chronic disease epidemiology: Conceptual models, empirical challenges and interdisciplinary perspectives. International Journal of Epidemiology, 31(2), 285-293. https://doi.org/10.1093/ije/31.2.285

Bergland, C. (2015). Loneliness: Perceived social isolation is public enemy no. 1. Psychology Today. Retrieved from https://www.psychologytoday.com/gb/blog/the-athletesway/201511/loneliness-perceived-social-isolation-is-public-enemy-no-1

Berkman, L. F. (1995). The role of social relations in health promotion. Psychosomatic Medicine, 57(3), 245-254. https://doi.org/10.1097/00006842-199505000-00006

Berkman, L. F., Glass, T., Brissette, I., \& Seeman, T. E. (2000). From social integration to health: Durkheim in the new millennium. Social Science \& Medicine, 51(6), 843-857. https://doi.org/10.1016/S0277-9536(00)00065-4

Berkman, L. F., \& Syme, S. L. (1979). Social networks, host resistance, and mortality: A nineyear follow-up study of Alameda County residents. American Journal of Epidemiology, 109(2), 186-204. https://doi.org/10.1093/oxfordjournals.aje.a112674 
Berscheid, E. (1999). The greening of relationship science. American psychologist, 54(4), 260266. https://doi.org/10.1037/0003-066X.54.4.260

Bettencourt, B., \& Sheldon, K. (2001). Social roles as mechanism for psychological need satisfaction within social groups. Journal of Personality and Social Psychology, 81(6), 1131-1143. https://doi.org/10.1037/0022-3514.81.6.1131

Bickart, K. C., Dickerson, B. C., \& Barrett, L. F. (2014). The amygdala as a hub in brain networks that support social life. Neuropsychologia, 63, 235-248. https://doi.org/10.1016/j.neuropsychologia.2014.08.013

Bickerdike, L., Booth, A., Wilson, P. M., Farley, K., \& Wright, K. (2017). Social prescribing: Less rhetoric and more reality. A systematic review of the evidence. BMJ Open, 7(4), e013384. https://doi.org/10.1136/bmjopen-2016-013384

Biddle, B. J. (1979). Role theory: Expectations, identities and behaviors. New York, NY: Academic Press.

Biddle, B. J. (1986). Recent developments in role theory. Annual Review of Sociology, 12(1), 6792. https://doi.org/10.1146/annurev.so.12.080186.000435

Blieszner, R. (2006). A lifetime of caring: Dimensions and dynamics in late-life close relationships. Personal Relationships, 13(1), 1-18. https://doi.org/10.1111/j.1475$\underline{6811.2006 .00101 . x}$

Bohnert, A. S., \& Ilgen, M. A. (2019). Understanding links among opioid use, overdose, and suicide. New England Journal of Medicine, 380(1), 71-79.

https://doi.org/10.1056/NEJMra1802148 
Bolger, N., DeLongis, A., Kessler, R. C., \& Wethington, E. (1989). The contagion of stress across multiple roles. Journal of Marriage and the Family, 51(1), 175-183. https://doi.org/10.2307/352378

Bollen, K. A. (2002). Latent variables in psychology and the social sciences. Annual Review of Psychology, 53(1), 605-634. https://doi.org/10.1146/annurev.psych.53.100901.135239

Borsboom, D., Mellenbergh, G. J., \& Van Heerden, J. (2003). The theoretical status of latent variables. Psychological Review, 110(2), 203-219. https://doi.org/10.1037/0033$\underline{295 X .110 .2 .203}$

Boss, L., Kang, D. H., \& Branson, S. (2015). Loneliness and cognitive function in the older adult: A systematic review. International Psychogeriatrics, 27(4), 541-553. https://doi.org/10.1017/S1041610214002749

Bound Alberti, F. (2018). This "modern epidemic": Loneliness as an emotion cluster and a neglected subject in the history of emotions. Emotion Review, 10(3), 242-254. https://doi.org/10.1177/1754073918768876

Bourdieu, P. (1985). The forms of social capital. In J. G. Richardson (Ed.), Handbook of theory and research for the sociology of education (pp. 241-258). New York, NY: Greenwood.

Bowlby, J. (1973). Attachment and loss: Vol. 2. Separation: Anxiety and anger. New York, NY: Basic Books.

Bowling, A. (2004). Measuring health: A review of quality of life measurement scales. Berkshire, UK: McGraw-Hill Education.

Bradbury, T. N., \& Bodenmann, G. (2020). Interventions for couples. Annual Review of Clinical Psychology, 16, 99-123. https://doi.org/10.1146/annurev-clinpsy-071519-020546 
Bradbury, T. N., \& Karney, B. R. (2019). Intimate relationships. New York, NY: W.W. Norton \& Company.

Branscombe, N. R., Schmitt, M. T., \& Harvey, R. D. (1999). Perceiving pervasive discrimination among African Americans: Implications for group identification and well-being. Journal of Personality and Social Psychology, 77(1), 135-149. https://doi.org/10.1037/0022-

\section{$\underline{3514.77 .1 .135}$}

Braveman, P. A., Kumanyika, S., Fielding, J., LaVeist, T., Borrell, L. N., Manderscheid, R., \& Troutman, A. (2011). Health disparities and health equity: The issue is justice. American Journal of Public Health, 101(1), S149-S155. https://doi.org/10.2105/AJPH.2010.300062

Breslow, L. (1972). A quantitative approach to the World Health Organization definition of health: Physical, mental and social well-being. International Journal of Epidemiology, 1(4), 347-355. https://doi.org/10.1093/ije/1.4.347

Breslow, L. (2006). Health measurement in the third era of health. American Journal of Public Health, 96(1), 17-19. https://doi.org/10.2105/AJPH.2004.055970

Brewer, M. B., \& Caporael, L. R. (1990). Selfish genes vs. selfish people: Sociobiology as origin myth. Motivation and Emotion, 14(4), 237-243. https://doi.org/10.1007/BF00996182

Broekens, J., Heerink, M., \& Rosendal, H. (2009). Assistive social robots in elderly care: A review. Gerontechnology, 8(2), 94-103. https://doi.org/10.4017/gt.2009.08.02.002.00

Bronfenbrenner, U. (1979). The ecology of human development. Cambridge, MA: Harvard University Press.

Brooks, K. P., \& Dunkel Schetter, C. (2011). Social negativity and health: Conceptual and measurement issues. Social and Personality Psychology Compass, 5(11), 904-918. https://doi.org/10.1111/j.1751-9004.2011.00395.x 
Brown, A. F., Vargas, R. B., Ang, A., \& Pebley, A. R. (2008). The neighborhood food resource environment and the health of residents with chronic conditions. Journal of General Internal Medicine, 23(8), 1137-1144. https://doi.org/10.1007/s11606-008-0601-5

Buettner, D., \& Skemp, S. (2016). Blue zones: Lessons from the world's longest lived. American Journal of Lifestyle Medicine, 10(5), 318-321. https://doi.org/10.1177/1559827616637066

Buchman, A. S., Boyle, P. A., Wilson, R. S., James, B. D., Leurgans, S. E., Arnold, S. E., \& Bennett, D. A. (2010). Loneliness and the rate of motor decline in old age: The Rush Memory and Aging Project, a community-based cohort study. BMC Geriatrics, 10(1), 1-8. https://doi.org/10.1186/1471-2318-10-77

Bui, C. N., Peng, C., Mutchler, J. E., \& Burr, J. A. (2021). Race and ethnic group disparities in emotional distress among older adults during the COVID-19 pandemic. The Gerontologist, 61(2), 262-272. https://doi.org/10.1093/geront/gnaa217

Bulanda, J. R., \& Brown, S. L. (2007). Race-ethnic differences in marital quality and divorce. Social Science Research, 36(3), 945-967. https://doi.org/10.1016/j.ssresearch.2006.04.001

Burton, A. M., Haley, W. E., \& Small, B. J. (2006). Bereavement after caregiving or unexpected death: Effects on elderly spouses. Aging and Mental Health, 10(3), 319-326. https://doi.org/10.1080/13607860500410045

Buss, D. M., \& Kenrick, D. T. (1998). Evolutionary social psychology. In D. T. Gilbert, S. T. Fiske, \& G. Lindzey (Eds.), The handbook of social psychology (4th ed., Vol. 2, pp. 9821026). New York, NY: McGraw-Hill.

Bzdok, D., \& Dunbar, R. I. M. (2020). The neurobiology of social distance. Trends in Cognitive Sciences, 24, 717-733. https://doi.org/10.1016/j.tics.2020.05.016 
Cacioppo, J. T., Berntson, G. G., Sheridan, J. F., \& McClintock, M. K. (2000). Multilevel integrative analyses of human behavior: Social neuroscience and the complementing nature of social and biological approaches. Psychological Bulletin, 126(6), 829.

https://doi.org/10.1037/0033-2909.126.6.829

Cacioppo, J. T., Cacioppo, S., Capitanio, J. P., \& Cole, S. W. (2015). The neuroendocrinology of social isolation. Annual Review of Psychology, 66, 733-767. https://doi.org/10.1146/annurev-psych-010814-015240

Cacioppo, J. T., Fowler, J. H., \& Christakis, N. A. (2009). Alone in the crowd: The structure and spread of loneliness in a large social network. Journal of Personality and Social Psychology, 97(6), 977-991. https://doi.org/10.1037/a0016076

Campbell, A. D. (2020). Practical implications of physical distancing, social isolation, and reduced physicality for older adults in response to COVID-19. Journal of Gerontological Social Work, 1-3. https://doi.org/10.1080/01634372.2020.1772933

Cance, J. D., Saavedra, L. M., Wondimu, B., Scaglione, N. M., Hairgrove, S., \& Graham, P. W. (2021). Examining the relationship between social connection and opioid misuse: A systematic review. Substance Use \& Misuse, 56(10), 1493-1507. https://doi.org/10.1080/10826084.2021.1936056

Cannon, W. B. (1929). Organization for physiological homeostasis. Physiological Reviews, 9(3), 399-431. https://doi.org/10.1152/physrev.1929.9.3.399

Carpiano, R. M. (2006). Toward a neighborhood resource-based theory of social capital for health: Can Bourdieu and sociology help?. Social Science \& Medicine, 62(1), 165-175. https://doi.org/10.1016/j.socscimed.2005.05.020 
Carter, C. S. (1998). Neuroendocrine perspectives on social attachment and love. Psychoneuroendocrinology, 23(8), 779-818. https://doi.org/10.1016/S0306$\underline{4530(98) 00055-9}$

Carter, C. S. (2014). Oxytocin pathways and the evolution of human behavior. Annual Review of Psychology, 65, 17-39. https://doi.org/10.1146/annurev-psych-010213-115110

Carter, E. D. (2015). Making the Blue Zones: Neoliberalism and nudges in public health promotion. Social Science \& Medicine, 133, 374-382.

https://doi.org/10.1016/j.socscimed.2015.01.019

Case, A., \& Deaton, A. (2020). Deaths of despair and the future of capitalism. Princeton University Press.

Cassel, J. (1976). The contribution of the social environment to host resistance: The Fourth Wade Hampton Frost Lecture. American Journal of Epidemiology, 104(2), 107-123. https://doi.org/10.1093/oxfordjournals.aje.a112281

Castel, L. D., Williams, K. A., Bosworth, H. B., Eisen, S. V., Hahn, E. A., Irwin, D. E., ... DeVellis, R. F. (2008). Content validity in the PROMIS social-health domain: A qualitative analysis of focus-group data. Quality of Life Research, 17(5), 737-749. https://doi.org/10.1007/s11136-008-9352-3

Cella, D., Yount, S., Rothrock, N., Gershon, R., Cook, K., Reeve, B., ... Rose, M. (2007). The Patient-Reported Outcomes Measurement Information System (PROMIS): Progress of an NIH Roadmap cooperative group during its first two years. Medical Care, 45(5), S3-S11. https://doi.org/10.1097/01.mlr.0000258615.42478.55 
Chan, C., Ying Ho, P. S., \& Chow, E. (2002). A body-mind-spirit model in health: An Eastern approach. Social Work in Health Care, 34(3-4), 261-282.

https://doi.org/10.1300/J010v34n03 02

Chan, H. Y., \& Lo, T. W. (2014). Quality of life of the hidden youth in Hong Kong. Applied Research in Quality of Life, 9(4), 951-969. https://doi.org/10.1007/s11482-013-9279-x

Chartrand, T. L., \& Bargh, J. A. (1999). The chameleon effect: The perception-behavior link and social interaction. Journal of Personality and Social Psychology, 76(6), 893-910. https://doi.org/10.1037//0022-3514.76.6.893

Chen, D., \& Yang, T. C. (2014). The pathways from perceived discrimination to self-rated health: An investigation of the roles of distrust, social capital, and health behaviors. Social Science \& Medicine, 104, 64-73. https://doi.org/10.1016/j.socscimed.2013.12.021

Chen, S., Boucher, H. C., \& Tapias, M. P. (2006). The relational self revealed: Integrative conceptualization and implications for interpersonal life. Psychological Bulletin, 132(2), 151-179. https://doi.org/10.1037/0033-2909.132.2.151

Chen, Z., Poon, K.-T., DeWall, C. N., \& Jiang, T. (2020). Life lacks meaning without acceptance: Ostracism triggers suicidal thoughts. Journal of Personality and Social Psychology, 119(6), 1423-1443. https://doi.org/10.1037/pspi0000238

Cho, I., \& Blaser, M. J. (2012). The human microbiome: At the interface of health and disease. Nature Reviews Genetics, 13(4), 260-270. https://doi.org/10.1038/nrg3182

Christakis, N. A., \& Fowler, J. H. (2007). The spread of obesity in a large social network over 32 years. New England Journal of Medicine, 357(4), 370-379.

https://doi.org/10.1056/NEJMsa066082 
Clark, M. S., \& Mills, J. (1979). Interpersonal attraction in exchange and communal relationships. Journal of Personality and Social Psychology, 37(1), 12-24. https://doi.org/10.1037/0022-3514.37.1.12

Cloud, D. H., Drucker, E., Browne, A., \& Parsons, J. (2015). Public health and solitary confinement in the United States. American Journal of Public Health, 105(1), 18-26. https://doi.org/10.2105/AJPH.2014.302205

Cobb, S. (1976). Social support as a moderator of life stress. Psychosomatic Medicine, 38(5), 300-314. https://doi.org/10.1097/00006842-197609000-00003

Cohen, S., \& Wills, T. A. (1985). Stress, social support, and the buffering hypothesis. Psychological Bulletin, 98(2), 310-357. https://doi.org/10.1037/0033-2909.98.2.310

Coleman, J. S. (1988). Social capital in the creation of human capital. American Journal of Sociology, 94(1), S95-S120. https://doi.org/10.1086/228943

Cooke, R. A., \& Rousseau, D. M. (1984). Stress and strain from family roles and work-role expectations. Journal of Applied Psychology, 69(2), 252-260. https://doi.org/10.1037/0021$\underline{9010.69 .2 .252}$

Cooley, C. H. (1902). The looking-glass self. In J. G. Manis, \& B. N. Meltzer (Eds.), Symbolic interaction: A reader in social psychology (pp. 217-219). Boston: Allyn \& Bacon.

Cornwell, E. Y., \& Waite, L. J. (2009). Social disconnectedness, perceived isolation, and health among older adults. Journal of Health and Social Behavior, 50(1), 31-48. https://doi.org/10.1177/002214650905000103

Coyle, C. E., \& Dugan, E. (2012). Social isolation, loneliness and health among older adults. Journal of Aging and Health, 24(8), 1346-1363. https://doi.org/10.1177/0898264312460275 
Cozolino, L. (2014). The neuroscience of human relationships: Attachment and the developing social brain. New York, NY: W. W. Norton.

Cummins, R. A. (2000). Objective and subjective quality of life: An interactive model. Social Indicators Research, 52(1), 55-72. https://doi.org/10.1023/A:1007027822521

Damasio, A. R. (1994). Descartes' error and the future of human life. Scientific American, 271(4), 144. https://doi.org/10.1038/scientificamerican1094-144

Dang, J., King, K. M., \& Inzlicht, M. (2020). Why are self-report and behavioral measures weakly correlated?. Trends in Cognitive Sciences, 24(4), 267-269. https://doi.org/10.1016/j.tics.2020.01.007

Daniel, K., Wolfe, C. D., Busch, M. A., \& McKevitt, C. (2009). What are the social consequences of stroke for working-aged adults? A systematic review. Stroke, 40(6), e431e440. https://doi.org/10.1161/STROKEAHA.108.534487

Dantzer, R., O'Connor, J. C., Freund, G. G., Johnson, R. W., \& Kelley, K. W. (2008). From inflammation to sickness and depression: When the immune system subjugates the brain. Nature Reviews Neuroscience, 9(1), 46-56. https://doi.org/10.1038/nrn2297

Davila, J., Bradbury, T. N., Cohan, C. L., \& Tochluk, S. (1997). Marital functioning and depressive symptoms: Evidence for a stress generation model. Journal of Personality and Social Psychology, 73(4), 849-861. https://doi.org/10.1037/0022-3514.73.4.849

De Dreu, C. K. (2012). Oxytocin modulates cooperation within and competition between groups: An integrative review and research agenda. Hormones and Behavior, 61(3), 419-428. https://doi.org/10.1016/j.yhbeh.2011.12.009 
Delaney, B. (2020). How will we tackle the pandemic of loneliness after Covid? The Guardian. Retrieved from https://www.theguardian.com/commentisfree/2020/oct/16/how-will-wetackle-the-pandemic-of-loneliness-after-covid

Derose, K. P., \& Varda, D. M. (2009). Social capital and health care access: A systematic review. Medical Care Research and Review, 66(3), 272-306. https://doi.org/10.1177/1077558708330428

Diener, E., Gohm, C. L., Suh, E., \& Oishi, S. (2000). Similarity of the relations between marital status and subjective well-being across cultures. Journal of Cross-Cultural Psychology, 31(4), 419-436. https://doi.org/10.1177/0022022100031004001

Diez-Roux, A. V. (2007). Integrating social and biologic factors in health research: A systems view. Annals of Epidemiology, 17(7), 569-574. https://doi.org/10.1016/j.annepidem.2007.03.001

Donald, C. A., \& Ware, J. E. (1982). The quantification of social contacts and resources. Santa Monica, CA: RAND Corporation.

Donald, C. A., Ware, J. E., Brook, R. H., \& Davies-Avery, A. (1978). Conceptualization and measurement of health for adults in the Health Insurance Study: Vol. IV, Social health. Santa Monica, CA: RAND Corporation.

Doyle, C., \& Cicchetti, D. (2017). From the cradle to the grave: The effect of adverse caregiving environments on attachment and relationships throughout the lifespan. Clinical Psychology: Science and Practice, 24(2), 203-217. https://doi.org/10.1111/cpsp.12192

Doyle, D. M., \& Barreto, M. (2021). Social stigma increases loneliness among ethnic minorities. Manuscript in preparation, University of Exeter. 
Doyle, D. M., Factor-Litvak, P., \& Link, B. G. (2018). Modeling racial disparities in physical health via close relationship functioning: A life course approach. Social Science \& Medicine, 204, 31-38. https://doi.org/10.1016/j.socscimed.2018.02.002

Doyle, D. M., \& Molix, L. (2014). How does stigma spoil relationships? Evidence that perceived discrimination harms romantic relationship quality through impaired self-image. Journal of Applied Social Psychology, 44(9), 600-610. https://doi.org/10.1111/jasp.12252

Doyle, D. M., \& Molix, L. (2014). Love on the margins: The effects of social stigma and relationship length on romantic relationship quality. Social Psychological and Personality Science, 5(1), 102-110. https://doi.org/10.1177/1948550613486677

Doyle, D. M., \& Molix, L. (2014). Perceived discrimination as a stressor for close relationships: Identifying psychological and physiological pathways. Journal of Behavioral Medicine, 37(6), 1134-1144. https://doi.org/10.1007/s10865-014-9563-8

Doyle, D. M., \& Molix, L. (2015). Social stigma and sexual minorities' romantic relationship functioning: A meta-analytic review. Personality and Social Psychology Bulletin, 41(10), 1363-1381. https://doi.org/10.1177/0146167215594592

Doyle, D. M., \& Molix, L. (2016). Disparities in social health by sexual orientation and the etiologic role of self-reported discrimination. Archives of Sexual Behavior, 45(6), 13171327. https://doi.org/10.1007/s10508-015-0639-5

Dufur, M. J., Parcel, T. L., \& Troutman, K. P. (2013). Does capital at home matter more than capital at school? Social capital effects on academic achievement. Research in Social Stratification and Mobility, 31, 1-21. https://doi.org/10.1016/j.rssm.2012.08.002

Dunbar, R. I. (1998). The social brain hypothesis. Evolutionary Anthropology, 6(5), 178-190. https://doi.org/10.1002/(SICI)1520-6505(1998)6:5<178::AID-EVAN5>3.0.CO;2-8 
Durkheim, E. (1963). Suicide. New York, NY: Free Press.

Ebaugh, H. R., \& Curry, M. (2000). Fictive kin as social capital in new immigrant communities. Sociological Perspectives, 43(2), 189-209. https://doi.org/10.2307/1389793

Eccles, A. M., \& Qualter, P. (2021). Alleviating loneliness in young people-a meta-analysis of interventions. Child and Adolescent Mental Health, 26(1), 17-33. https://doi.org/10.1111/camh.12389

Efferth, T., Banerjee, M., \& Paul, N. W. (2017). Broken heart, tako-tsubo or stress cardiomyopathy? Metaphors, meanings and their medical impact. International Journal of Cardiology, 230, 262-268. https://doi.org/10.1016/j.ijcard.2016.12.129

Ehsan, A., Klaas, H. S., Bastianen, A., \& Spini, D. (2019). Social capital and health: A systematic review of systematic reviews. SSM-Population Health, 8, 100425. https://doi.org/10.1016/j.ssmph.2019.100425

Eisenberger, N. I., \& Cole, S. W. (2012). Social neuroscience and health: Neurophysiological mechanisms linking social ties with physical health. Nature Neuroscience, 15(5), 669-674. https://doi.org/10.1038/nn.3086

Eisenberger, N. I., Inagaki, T. K., Mashal, N. M., \& Irwin, M. R. (2010). Inflammation and social experience: An inflammatory challenge induces feelings of social disconnection in addition to depressed mood. Brain, Behavior, and Immunity, 24(4), 558-563. https://doi.org/10.1016/j.bbi.2009.12.009

Eisenberger, N. I., Lieberman, M. D., \& Williams, K. D. (2003). Does rejection hurt? An fMRI study of social exclusion. Science, 302(5643), 290-292.

https://doi.org/10.1126/science.1089134 
El-Sayed, A. M., Scarborough, P., Seemann, L., \& Galea, S. (2012). Social network analysis and agent-based modeling in social epidemiology. Epidemiologic Perspectives \& Innovations, 9(1), 1-9. https://doi.org/10.1186/1742-5573-9-1

Elwert, F., \& Christakis, N. A. (2008). The effect of widowhood on mortality by the causes of death of both spouses. American Journal of Public Health, 98(11), 2092-2098. https://doi.org/10.2105/AJPH.2007.114348

Emerson, K., Boggero, I., Ostir, G., \& Jayawardhana, J. (2018). Pain as a risk factor for loneliness among older adults. Journal of Aging and Health, 30(9), 1450-1461. https://doi.org/10.1177/0898264317721348

Engel, G. L. (1977). The need for a new medical model: A challenge for biomedicine. Science, 196(4286), 129-136. https://doi.org/10.1126/science.847460

Ertel, K. A., Glymour, M. M., \& Berkman, L. F. (2009). Social networks and health: A life course perspective integrating observational and experimental evidence. Journal of Social and Personal Relationships, 26(1), 73-92. https://doi.org/10.1177/0265407509105523

Evans, A. S. (1976). Causation and disease: the Henle-Koch postulates revisited. The Yale Journal of Biology and Medicine, 49(2), 175-195.

Falci, C., \& McNeely, C. (2009). Too many friends: Social integration, network cohesion and adolescent depressive symptoms. Social Forces, 87(4), 2031-2061. https://doi.org/10.1353/sof.0.0189

Fearon, R. P., \& Roisman, G. I. (2017). Attachment theory: Progress and future directions. Current Opinion in Psychology, 15, 131-136.

https://doi.org/10.1016/j.copsyc.2017.03.002 
Feeney, B. C., \& Collins, N. L. (2014). A theoretical perspective on the importance of social connections for thriving. In M. Mikulincer \& P. R. Shaver (Eds.), The Herzliya series on personality and social psychology. Mechanisms of social connection: From brain to group (pp. 291-314). Washington, DC: American Psychological Association. http://dx.doi.org/10.1037/14250-017

Feldman, R. (2007). Parent-infant synchrony: Biological foundations and developmental outcomes. Current Directions in Psychological Science, 16(6), 340-345. https://doi.org/10.1111/j.1467-8721.2007.00532.x

Feldman, R. (2017). The neurobiology of human attachments. Trends in Cognitive Sciences, 21(2), 80-99. https://doi.org/10.1016/j.tics.2016.11.007

Feldman, R., \& Bakermans-Kranenburg, M. J. (2017). Oxytocin: A parenting hormone. Current Opinion in Psychology, 15, 13-18. https://doi.org/10.1016/j.copsyc.2017.02.011

Finnell, J. E., \& Wood, S. K. (2016). Neuroinflammation at the interface of depression and cardiovascular disease: Evidence from rodent models of social stress. Neurobiology of Stress, 4, 1-14. https://doi.org/10.1016/j.ynstr.2016.04.001

Fiori, K. L., Antonucci, T. C., \& Cortina, K. S. (2006). Social network typologies and mental health among older adults. The Journals of Gerontology Series B: Psychological Sciences and Social Sciences, 61(1), P25-P32. https://doi.org/10.1093/geronb/61.1.P25

Fiorillo, D., \& Sabatini, F. (2011). Quality and quantity: the role of social interactions in selfreported individual health. Social Science \& Medicine, 73(11), 1644-1652. https://doi.org/10.1016/j.socscimed.2011.09.007 
Fisher, A. N., Stinson, D. A., Wood, J. V., Holmes, J. G., \& Cameron, J. J. (2021). Singlehood and attunement of self-esteem to friendships. Social Psychological and Personality Science, 1-9. https://doi.org/10.1177/1948550620988460

Fiske, S. T. (1993). Social cognition and social perception. Annual Review of Psychology, 44(1), 155-194. https://doi.org/10.1146/annurev.ps.44.020193.001103

Fitzsimons, G. M., \& Bargh, J. A. (2003). Thinking of you: Nonconscious pursuit of interpersonal goals associated with relationship partners. Journal of Personality and Social Psychology, 84(1), 148-164. https://doi.org/10.1037/0022-3514.84.1.148

Flake, J. K., \& Fried, E. I. (2020). Measurement schmeasurement: Questionable measurement practices and how to avoid them. Advances in Methods and Practices in Psychological Science, 3(4), 456-465. https://doi.org/10.1177/2515245920952393

Fletcher, G. J., Simpson, J. A., \& Thomas, G. (2000). The measurement of perceived relationship quality components: A confirmatory factor analytic approach. Personality and Social Psychology Bulletin, 26(3), 340-354. https://doi.org/10.1177/0146167200265007

Flores, E. C., Fuhr, D. C., Bayer, A. M., Lescano, A. G., Thorogood, N., \& Simms, V. (2018). Mental health impact of social capital interventions: A systematic review. Social Psychiatry and Psychiatric Epidemiology, 53(2), 107-119. https://doi.org/10.1007/s00127$\underline{017-1469-7}$

Folk, D., Okabe-Miyamoto, K., Dunn, E., Lyubomirsky, S., \& Donnellan, B. (2020). Did social connection decline during the first wave of COVID-19?: The role of extraversion. Collabra: Psychology, 6(1), 37. https://doi.org/10.1525/collabra.365 
Ford, M. B. (2020). Social distancing during the COVID-19 pandemic as a predictor of daily psychological, social, and health-related outcomes. The Journal of General Psychology, 123. https://doi.org/10.1080/00221309.2020.1860890

Fraley, R. C. (2002). Attachment stability from infancy to adulthood: Meta-analysis and dynamic modeling of developmental mechanisms. Personality and Social Psychology Review, 6(2), 123-151. https://doi.org/10.1207/S15327957PSPR0602_03

Fried, E. I. (2017). What are psychological constructs? On the nature and statistical modelling of emotions, intelligence, personality traits and mental disorders. Health Psychology Review, 11(2), 130-134. https://doi.org/10.31234/osf.io/xpu4z

Frost, D. M., Meyer, I. H., \& Schwartz, S. (2016). Social support networks among diverse sexual minority populations. American Journal of Orthopsychiatry, 86(1), 91-102. https://doi.org/10.1037/ort0000117

Fukuyama, F. (2001). Social capital, civil society and development. Third World Quarterly, 22(1), 7-20. https://doi.org/10.1080/713701144

Fulton, L., \& Jupp, B. (2015). Investing to tackle loneliness: A discussion paper. London, UK: Social Finance.

Funk, J. L., \& Rogge, R. D. (2007). Testing the ruler with item response theory: Increasing precision of measurement for relationship satisfaction with the Couples Satisfaction Index. Journal of Family Psychology, 21(4), 572-583. https://doi.org/10.1037/0893$\underline{3200.21 .4 .572}$

Furman, D., Campisi, J., Verdin, E., Carrera-Bastos, P., Targ, S., Franceschi, C., ... Slavich, G. M. (2019). Chronic inflammation in the etiology of disease across the life span. Nature Medicine, 25(12), 1822-1832. https://doi.org/10.1038/s41591-019-0675-0 
Gabriel, S., \& Gardner, W. L. (1999). Are there" his" and" hers" types of interdependence? The implications of gender differences in collective versus relational interdependence for affect, behavior, and cognition. Journal of Personality and Social Psychology, 77(3), 642655. https://doi.org/10.1037/0022-3514.77.3.642

Galea, S., Merchant, R. M., \& Lurie, N. (2020). The mental health consequences of COVID-19 and physical distancing: The need for prevention and early intervention. JAMA Internal Medicine, 180(6), 817-818. https://doi.org/10.1001/jamainternmed.2020.1562

Gardiner, C., Geldenhuys, G., \& Gott, M. (2018). Interventions to reduce social isolation and loneliness among older people: An integrative review. Health \& Social Care in the Community, 26(2), 147-157. https://doi.org/10.1111/hsc.12367

Gauthier, G. R., Smith, J. A., García, C., Garcia, M. A., \& Thomas, P. A. (2021). Exacerbating inequalities: Social networks, racial/ethnic disparities, and the COVID-19 pandemic in the United States. The Journals of Gerontology: Series B, 76(3), e88-e92. https://doi.org/10.1093/geronb/gbaa117

Ghaemi, S. N. (2011). The biopsychosocial model in psychiatry: A critique. American Journal of Psychiatry, 121, 451-7.

Giger, J. C., Piçarra, N., Alves-Oliveira, P., Oliveira, R., \& Arriaga, P. (2019). Humanization of robots: Is it really such a good idea?. Human Behavior and Emerging Technologies, 1(2), 111-123. https://doi.org/10.1002/hbe2.147

Glenn, N. D., \& Weaver, C. N. (1981). The contribution of marital happiness to global happiness. Journal of Marriage and the Family, 43(1), 161-168. https://doi.org/10.2307/351426 
Greenaway, K. H., Cruwys, T., Haslam, S. A., \& Jetten, J. (2016). Social identities promote well-being because they satisfy global psychological needs. European Journal of Social Psychology, 46(3), 294-307. https://doi.org/10.1002/ejsp.2169

Greenaway, K. H., Haslam, S. A., Cruwys, T., Branscombe, N. R., Ysseldyk, R., \& Heldreth, C. (2015). From "we" to "me": Group identification enhances perceived personal control with consequences for health and well-being. Journal of Personality and Social Psychology, 109(1), 53-74. https://doi.org/10.1037/pspi0000019

Griffin, D. W., \& Ross, L. (1991). Subjective construal, social inference, and human misunderstanding. In M. P. Zanna (Ed.), Advances in experimental social psychology (Vol. 24, pp. 319-359). San Diego, CA: Academic Press.

Griffin, S. C., Williams, A. B., Ravyts, S. G., Mladen, S. N., \& Rybarczyk, B. D. (2020). Loneliness and sleep: A systematic review and meta-analysis. Health Psychology Open, 7(1), 1-11. https://doi.org/10.1177/2055102920913235

Guillemin, M., \& Barnard, E. (2015). George Libman Engel: The biopsychosocial model and the construction of medical practice. In F. Collyer (Ed.), The Palgrave handbook of social theory in health, illness and medicine (pp. 236-250). London: Palgrave Macmillan. https://doi.org/10.1057/9781137355621_15

Guyatt, G. H., Feeny, D. H., \& Patrick, D. L. (1993). Measuring health-related quality of life. Annals of Internal Medicine, 118(8), 622-629. https://doi.org/10.7326/0003-4819$\underline{118-8-199304150-00009}$

Hahn, E. A., DeVellis, R. F., Bode, R. K., Garcia, S. F., Castel, L. D., Eisen, S. V., ... \& Cella, D. (2010). Measuring social health in the Patient-Reported Outcomes Measurement 
Information System (PROMIS): Item bank development and testing. Quality of Life Research, 19(7), 1035-1044. https://doi.org/10.1007/s11136-010-9654-0

Hampton, K. N., \& Wellman, B. (2018). Lost and saved... again: The moral panic about the loss of community takes hold of social media. Contemporary Sociology, 47(6), 643-651. https://doi.org/10.1177/0094306118805415

Harpham, T., Grant, E., \& Thomas, E. (2002). Measuring social capital within health surveys: Key issues. Health Policy and Planning, 17(1), 106-111. https://doi.org/10.1093/heapol/17.1.106

Harrison, A. O., Wilson, M. N., Pine, C. J., Chan, S. Q., \& Buriel, R. (1990). Family ecologies of ethnic minority children. Child Development, 61(2), 347-362. https://doi.org/10.1111/j.1467-8624.1990.tb02782.x

Hashemi, F. M., Pourmalek, F., Tehrani, A., Abachizadeh, K., Memaryan, N., Hazar, N., ... Lakeh, M. M. (2016). Monitoring social well-being in Iran. Social Indicators Research, 129(1), 1-12. https://doi.org/10.1007/s11205-015-1087-2

Haslam, C., Cruwys, T., Milne, M., Kan, C. H., \& Haslam, S. A. (2016). Group ties protect cognitive health by promoting social identification and social support. Journal of Aging and Health, 28(2), 244-266. https://doi.org/10.1177/0898264315589578

Haslam, C., Jetten, J., Cruwys, T., Dingle, G., \& Haslam, S. A. (2018). The new psychology of health: Unlocking the social cure. London, UK: Routledge.

Haslam, S. A., Haslam, C., Jetten, J., Cruwys, T., \& Bentley, S. (2019). Group life shapes the psychology and biology of health: The case for a sociopsychobio model. Social and Personality Psychology Compass, 13(8), 1-16. https://doi.org/10.1111/spc3.12490 
Haslam, S. A., Jetten, J., Postmes, T., \& Haslam, C. (2009). Social identity, health and wellbeing: An emerging agenda for applied psychology. Applied Psychology: An International Review, 58(1), 1-23. https://doi.org/10.1111/j.1464-0597.2008.00379.x

Hatfield, E. (2006). The Golden Fleece Award: Love's labours almost lost. Observer, 19(6), 1617.

Hatfield, E., \& Sprecher, S. (1986). Measuring passionate love in intimate relationships. Journal of Adolescence, 9(4), 383-410. https://doi.org/10.1016/S0140-1971(86)80043-4

Hatzenbuehler, M. L., Phelan, J. C., \& Link, B. G. (2013). Stigma as a fundamental cause of population health inequalities. American Journal of Public Health, 103(5), 813-821. https://doi.org/10.2105/AJPH.2012.301069

Havranek, E. P., Mujahid, M. S., Barr, D. A., Blair, I. V., Cohen, M. S., Cruz-Flores, S., ... Yancy, C. W. (2015). Social determinants of risk and outcomes for cardiovascular disease: A scientific statement from the American Heart Association. Circulation, 132(9), 873-898. https://doi.org/10.1161/CIR.0000000000000228

Hawkley, L. C., \& Cacioppo, J. T. (2010). Loneliness matters: A theoretical and empirical review of consequences and mechanisms. Annals of Behavioral Medicine, 40(2), 218-227. https://doi.org/10.1007/s12160-010-9210-8

Hawkley, L. C., \& Capitanio, J. P. (2015). Perceived social isolation, evolutionary fitness and health outcomes: A lifespan approach. Philosophical Transactions of the Royal Society B: Biological Sciences, 370(1669), 20140114. https://doi.org/10.1098/rstb.2014.0114

Hawkley, L. C., Hughes, M. E., Waite, L. J., Masi, C. M., Thisted, R. A., \& Cacioppo, J. T. (2008). From social structural factors to perceptions of relationship quality and loneliness: The Chicago health, aging, and social relations study. The Journals of Gerontology Series 
B: Psychological Sciences and Social Sciences, 63(6), S375-S384. https://doi.org/10.1093/geronb/63.6.S375

Hawton, A., Green, C., Dickens, A. P., Richards, S. H., Taylor, R. S., Edwards, R., ... Campbell, J. L. (2011). The impact of social isolation on the health status and health-related quality of life of older people. Quality of Life Research, 20(1), 57-67. https://doi.org/10.1007/s11136$\underline{010-9717-2}$

Hazan, C., \& Shaver, P. R. (1994). Attachment as an organizational framework for research on close relationships. Psychological Inquiry, 5(1), 1-22. https://doi.org/10.1207/s15327965pli0501_1

Heaney, C.A., \& Israel, B.A. (2008). Social networks and social support. In K. Glanz, B. K. Rimer \& K. Viswanath (Eds.), Health behavior and health education: Theory, research, and practice (4th ed., Vol. 4, pp. 189-210). San Francisco, CA: Jossey-Bass.

Heid, A. R., Cartwright, F., Wilson-Genderson, M., \& Pruchno, R. (2021). Challenges experienced by older people during the initial months of the COVID-19 pandemic. The Gerontologist, 61(1), 48-58. https://doi.org/10.1093/geront/gnaa138

Heidinger, T., \& Richter, L. (2020). The effect of COVID-19 on loneliness in the elderly. An empirical comparison of pre-and peri-pandemic loneliness in community-dwelling elderly. Frontiers in Psychology, 11, 2595. https://doi.org/10.3389/fpsyg.2020.585308

Heinrich, L. M., \& Gullone, E. (2006). The clinical significance of loneliness: A literature review. Clinical Psychology Review, 26(6), 695-718. https://doi.org/10.1016/j.cpr.2006.04.002 
Helm, J. L., Sbarra, D., \& Ferrer, E. (2012). Assessing cross-partner associations in physiological responses via coupled oscillator models. Emotion, 12(4), 748-762. https://doi.org/10.1037/a0025036

Helm, J. L., Sbarra, D. A., \& Ferrer, E. (2014). Coregulation of respiratory sinus arrhythmia in adult romantic partners. Emotion, 14(3), 522-531. https://doi.org/10.1037/a0035960

Hinchliffe, S., Jackson, M. A., Wyatt, K., Barlow, A. E., Barreto, M., Clare, L., ... Thomas, F. (2018). Healthy publics: Enabling cultures and environments for health. Palgrave Communications, 4(1), 1-10. https://doi.org/10.1057/s41599-018-0113-9

Hobbs, W. R., \& Burke, M. K. (2017). Connective recovery in social networks after the death of a friend. Nature Human Behaviour, 1(5), 1-6. https://doi.org/10.1038/s41562-017-0092

Hofmann, H. A., Beery, A. K., Blumstein, D. T., Couzin, I. D., Earley, R. L., Hayes, L. D., ... \& Rubenstein, D. R. (2014). An evolutionary framework for studying mechanisms of social behavior. Trends in Ecology \& Evolution, 29(10), 581-589. https://doi.org/10.1016/j.tree.2014.07.008

Hogan, B. E., Linden, W., \& Najarian, B. (2002). Social support interventions: Do they work?. Clinical Psychology Review, 22(3), 381-440. https://doi.org/10.1016/S0272$\underline{7358(01) 00102-7}$

Holt-Lunstad, J. (2017). The potential public health relevance of social isolation and loneliness: Prevalence, epidemiology, and risk factors. Public Policy \& Aging Report, 27(4), 127-130. https://doi.org/10.1093/ppar/prx030

Holt-Lunstad, J. (2018). Why social relationships are important for physical health: A systems approach to understanding and modifying risk and protection. Annual Review of Psychology, 69, 437-458. https://doi.org/10.1146/annurev-psych-122216-011902 
Holt-Lunstad, J. (2021). A pandemic of social isolation?. World Psychiatry, 20(1), 55-56. https://doi.org/10.1002/wps.20839

Holt-Lunstad, J., Birmingham, W. A., \& Light, K. C. (2008). Influence of a "warm touch" support enhancement intervention among married couples on ambulatory blood pressure, oxytocin, alpha amylase, and cortisol. Psychosomatic Medicine, 70(9), 976-985. https://doi.org/10.1097/PSY.0b013e318187aef7

Holt-Lunstad, J., Robles, T. F., \& Sbarra, D. A. (2017). Advancing social connection as a public health priority in the United States. American Psychologist, 72(6), 517-530. https://doi.org/10.1037/amp0000103

Holt-Lunstad, J., Smith, T. B., Baker, M., Harris, T., \& Stephenson, D. (2015). Loneliness and social isolation as risk factors for mortality: A meta-analytic review. Perspectives on Psychological Science, 10(2), 227-237. https://doi.org/10.1177/1745691614568352

Holt-Lunstad, J., Smith, T. B., \& Layton, J. B. (2010). Social relationships and mortality risk: A meta-analytic review. PLoS Medicine, 7(7), e1000316. https://doi.org/10.1371/journal.pmed.1000316

Hostinar, C. E., Sullivan, R. M., \& Gunnar, M. R. (2014). Psychobiological mechanisms underlying the social buffering of the hypothalamic-pituitary-adrenocortical axis: A review of animal models and human studies across development. Psychological Bulletin, 140(1), 256-282. https://doi.org/10.1037/a0032671

House, J. S., Landis, K. R., \& Umberson, D. (1988). Social relationships and health. Science, 241(4865), 540-545. https://doi.org/10.1126/science.3399889

House, J. S., Robbins, C., \& Metzner, H. L. (1982). The association of social relationships and activities with mortality: Prospective evidence from the Tecumseh Community Health 
Study. American Journal of Epidemiology, 116(1), 123-140.

https://doi.org/10.1093/oxfordjournals.aje.a113387

House, J. S., Umberson, D., \& Landis, K. R. (1988). Structures and processes of social support. Annual Review of Sociology, 14(1), 293-318. https://doi.org/10.1146/annurev.so.14.080188.001453

Inagaki, T. K. (2018). Opioids and social connection. Current Directions in Psychological Science, 27(2), 85-90. https://doi.org/10.1177/0963721417735531

Inagaki, T. K., Muscatell, K. A., Irwin, M. R., Cole, S. W., \& Eisenberger, N. I. (2012). Inflammation selectively enhances amygdala activity to socially threatening images. NeuroImage, 59(4), 3222-3226. https://doi.org/10.1016/j.neuroimage.2011.10.090

Ingram, I., Kelly, P. J., Deane, F. P., Baker, A. L., Goh, M. C., Raftery, D. K., \& Dingle, G. A. (2020). Loneliness among people with substance use problems: A narrative systematic review. Drug and Alcohol Review, 39(5), 447-483. https://doi.org/10.1111/dar.13064

Insel, T. R. (2010). The challenge of translation in social neuroscience: A review of oxytocin, vasopressin, and affiliative behavior. Neuron, 65(6), 768-779. https://doi.org/10.1016/j.neuron.2010.03.005

Insel, T. R., \& Fernald, R. D. (2004). How the brain processes social information: Searching for the social brain. Annual Review of Neuroscience, 27, 697-722. https://doi.org/10.1146/annurev.neuro.27.070203.144148

Institute of Medicine. (2014). Capturing social and behavioral domains and measures in electronic health records: Phase 2. Washington, DV: National Academies Press. http://dx.doi.org/10.17226/18951

James, W. (1890). The principles of psychology. New York, NY: Cosimo Inc. 
Jaremka, L. M., Andridge, R. R., Fagundes, C. P., Alfano, C. M., Povoski, S. P., Lipari, A. M., ... \& Kiecolt-Glaser, J. K. (2014). Pain, depression, and fatigue: Loneliness as a longitudinal risk factor. Health Psychology, 33(9), 948-957. https://doi.org/10.1037/a0034012

Jaremka, L. M., Lindgren, M. E., \& Kiecolt-Glaser, J. K. (2013). Synergistic relationships among stress, depression, and troubled relationships: Insights from psychoneuroimmunology. Depression and Anxiety, 30(4), 288-296. https://doi.org/10.1002/da.22078

Jeste, D. V., Lee, E. E., \& Cacioppo, S. (2020). Battling the modern behavioral epidemic of loneliness: Suggestions for research and interventions. JAMA Psychiatry, 77(6), 553-554. https://doi.org/10.1001/jamapsychiatry.2020.0027

Jetten, J., Branscombe, N. R., Haslam, S. A., Haslam, C., Cruwys, T., Jones, J. M., ... Zhang, A. (2015). Having a lot of a good thing: Multiple important group memberships as a source of self-esteem. PLoS One, 10(5), e0124609. https://doi.org/10.1371/journal.pone.0124609

Jetten, J., Haslam, C., \& Haslam, S. A. (2012). The social cure: Identity, health and well-being. Hove, UK: Psychology Press.

Johnson, S. B. (2013). Increasing psychology's role in health research and health care. American Psychologist, 68(5), 311-321. https://doi.org/10.1037/a0033591

Jones, J. M., \& Jetten, J. (2011). Recovering from strain and enduring pain: Multiple group memberships promote resilience in the face of physical challenges. Social Psychological and Personality Science, 2(3), 239-244. https://doi.org/10.1177/1948550610386806

Karunamuni, N., Imayama, I., \& Goonetilleke, D. (2020). Pathways to well-being: Untangling the causal relationships among biopsychosocial variables. Social Science \& Medicine, 272, 112846. https://doi.org/10.1016/j.socscimed.2020.112846 
Kato, T. A., Kanba, S., \& Teo, A. R. (2018). Hikikomori: Experience in Japan and international relevance. World Psychiatry, 17(1), 105-106. https://doi.org/10.1002/wps.20497

Kato, T. A., Kanba, S., \& Teo, A. R. (2019). Hikikomori: Multidimensional understanding, assessment, and future international perspectives. Psychiatry and Clinical Neurosciences, 73(8), 427-440. https://doi.org/10.1111/pcn.12895

Kelley, H. H., Berscheid, E., Christensen, A., Harvey, J. H., Huston, T. L., Levinger, G., . . . Peterson, D. R. (1983). Analyzing close relationships. In H. H. Kelley E. Berscheid, A. Christensen, J. H. Harvey, T. L. Huston, G. Levinger, E. McClintock, \& L. A. Peplau (Eds.), Close relationships (pp. 20-67). New York, NY: Freeman.

Kellezi, B., Wakefield, J. R. H., Stevenson, C., McNamara, N., Mair, E., Bowe, M., ... Halder, M. M. (2019). The social cure of social prescribing: A mixed-methods study on the benefits of social connectedness on quality and effectiveness of care provision. $B M J$ Open, 9(11), e033137. https://doi.org/10.1136/bmjopen-2019-033137

Keyes, C. L. M. (1998). Social well-being. Social Psychology Quarterly, 61(2), 121-140. https://doi.org/10.2307/2787065

Keyes, C. L. M., \& Shapiro, A. D. (2004). Social well-being in the United States: A descriptive epidemiology. In O. G. Brim, C. D. Ryff, \& R. Kessler (Eds.), How healthy are we? A national study of well-being at midlife (pp. 350-372). Chicago, IL: University of Chicago Press.

Kiecolt-Glaser, J. K., Fisher, L. D., Ogrocki, P., Stout, J. C., Speicher, C. E., \& Glaser, R. (1987). Marital quality, marital disruption, and immune function. Psychosomatic Medicine, 49(1), 13-34. https://doi.org/10.1097/00006842-198701000-00002 
Kim, J., \& Lee, J. E. R. (2011). The Facebook paths to happiness: Effects of the number of Facebook friends and self-presentation on subjective well-being. Cyberpsychology, Behavior, and Social Networking, 14(6), 359-364. https://doi.org/10.1089/cyber.2010.0374

Klinenberg, E. (2018). Is loneliness a health epidemic?. New York Times. Retrieved from https://www.nytimes.com/2018/02/09/opinion/sunday/loneliness-health.html

Kovacs, B., Caplan, N., Grob, S., \& King, M. (2021). Social networks and loneliness during the COVID-19 pandemic. Socius, 7, 1-16. https://doi.org/10.1177/2378023120985254

Krendl, A. C., \& Perry, B. L. (2021). The impact of sheltering in place during the COVID-19 pandemic on older adults' social and mental well-being. The Journals of Gerontology: Series B, 76(2), e53-e58. https://doi.org/10.1093/geronb/gbaa110

Krokfors, K. (2012). Co-housing in the making. Built Environment, 38(2), 308-314.

Kross, E., Verduyn, P., Sheppes, G., Costello, C. K., Jonides, J., \& Ybarra, O. (2020). Social media and well-being: Pitfalls, progress, and next steps. Trends in Cognitive Sciences, 25(1), 55-66. https://doi.org/10.1016/j.tics.2020.10.005

Kumsta, R., Hummel, E., Chen, F. S., \& Heinrichs, M. (2013). Epigenetic regulation of the oxytocin receptor gene: Implications for behavioral neuroscience. Frontiers in Neuroscience, 7, 83. https://doi.org/10.3389/fnins.2013.00083

Kyprianides, A., Easterbrook, M. J., \& Brown, R. (2019). Group identities benefit well-being by satisfying needs. Journal of Experimental Social Psychology, 84, Article 103836. https://doi.org/10.1016/j.jesp.2019.103836

La Guardia, J. G., Ryan, R. M., Couchman, C. E., \& Deci, E. L. (2000). Within-person variation in security of attachment: A self-determination theory perspective on attachment, need 
fulfillment, and well-being. Journal of Personality and Social Psychology, 79(3), 367-384. https://doi.org/10.1037/0022-3514.79.3.367

Lamm, C., \& Majdandžić, J. (2015). The role of shared neural activations, mirror neurons, and morality in empathy-A critical comment. Neuroscience Research, 90, 15-24. https://doi.org/10.1016/j.neures.2014.10.008

Larson, J. S. (1993). The measurement of social well-being. Social Indicators Research, 28(3), 285-296. https://doi.org/10.1007/BF01079022

Larson, J. S. (1996). The World Health Organization's definition of health: Social versus spiritual health. Social Indicators Research, 38(2), 181-192. https://doi.org/10.1007/BF00300458

Larson, J. S. (1999). The conceptualization of health. Medical Care Research and Review, 56(2), 123-136. https://doi.org/10.1177/107755879905600201

Leary, M. R., \& Baumeister, R. F. (2000). The nature and function of self-esteem: Sociometer theory. In M. P. Zanna (Ed.), Advances in experimental social psychology (Vol. 32, pp. 162). New York, NY: Academic Press. http://dx.doi.org/10.1016/S0065-2601(00)80003-9

Lee, C. M., Cadigan, J. M., \& Rhew, I. C. (2020). Increases in loneliness among young adults during the COVID-19 pandemic and association with increases in mental health problems. Journal of Adolescent Health, 67(5), 714-717.

https://doi.org/10.1016/j.jadohealth.2020.08.009

Lee, C. R., Chen, A., \& Tye, K. M. (2021). The neural circuitry of social homeostasis: Consequences of acute versus chronic social isolation. Cell, 184(6), 1500-1516. https://doi.org/10.1016/j.cell.2021.02.028 
Lehman, D. R., Wortman, C. B., \& Williams, A. F. (1987). Long-term effects of losing a spouse or child in a motor vehicle crash. Journal of Personality and Social Psychology, 52(1), 218-231. https://doi.org/10.1037/0022-3514.52.1.218

Leigh-Hunt, N., Bagguley, D., Bash, K., Turner, V., Turnbull, S., Valtorta, N., \& Caan, W. (2017). An overview of systematic reviews on the public health consequences of social isolation and loneliness. Public Health, 152, 157-171. https://doi.org/10.1016/j.puhe.2017.07.035

Libby, P. (2006). Inflammation and cardiovascular disease mechanisms. The American Journal of Clinical Nutrition, 83(2), 456S-460S. https://doi.org/10.1093/ajcn/83.2.456S

Lin, N. (2000). Inequality in social capital. Contemporary Sociology, 29(6), 785-795. https://doi.org/10.2307/2654086

Lindau, S. T., Laumann, E. O., Levinson, W., \& Waite, L. J. (2003). Synthesis of scientific disciplines in pursuit of health: The Interactive Biopsychosocial Model. Perspectives in Biology and Medicine, 46(3), 74-86. https://doi.org/10.1353/pbm.2003.005

Link, B. G., \& Phelan, J. (1995). Social conditions as fundamental causes of disease. Journal of Health and Social Behavior, 80-94. https://doi.org/10.2307/2626958

Liu, J., Beaujot, R., \& Ravanera, Z. (2018). Measuring the effects of stress and social networks on the health of Canadians. Applied Research in Quality of Life, 13(4), 891-908. https://doi.org/10.1007/s11482-017-9565-0

Liu, W. M., Forbat, L., \& Anderson, K. (2019). Death of a close friend: Short and long-term impacts on physical, psychological and social well-being. PLoS One, 14(4), e0214838. https://doi.org/10.1371/journal.pone.0214838 
Lu, J., Yu, Z., Zhang, X., Wu, M., Lin, S., Zhu, Y., ... Chen, K. (2020). Association between social health status and health-related quality of life among community-dwelling elderly in Zhejiang. Health and Quality of Life Outcomes, 18, 1-8. https://doi.org/10.1186/s12955$\underline{020-01358-4}$

Luchetti, M., Lee, J. H., Aschwanden, D., Sesker, A., Strickhouser, J. E., Terracciano, A., \& Sutin, A. R. (2020). The trajectory of loneliness in response to COVID-19. American Psychologist, 75(7), 897-908. https://doi.org/10.1037/amp0000690

Luigi, M., Dellazizzo, L., Giguère, C. É., Goulet, M. H., \& Dumais, A. (2020). Shedding light on "the Hole": A systematic review and meta-analysis on adverse psychological effects and mortality following solitary confinement in correctional settings. Frontiers in Psychiatry, 11, 840. https://doi.org/10.3389/fpsyt.2020.00840

Luong, G., Charles, S. T., \& Fingerman, K. L. (2011). Better with age: Social relationships across adulthood. Journal of Social and Personal Relationships, 28(1), 9-23. https://doi.org/10.1177/0265407510391362

Machin, A. J., \& Dunbar, R. I. (2011). The brain opioid theory of social attachment: A review of the evidence. Behaviour, 148(9-10), 985-1025. https://doi.org/10.1163/000579511X596624

MacLean, E. L., Wilson, S. R., Martin, W. L., Davis, J. M., Nazarloo, H. P., \& Carter, C. S. (2019). Challenges for measuring oxytocin: The blind men and the elephant?. Psychoneuroendocrinology, 107, 225-231. https://doi.org/10.1016/j.psyneuen.2019.05.018 Mahon, N. E., Yarcheski, A., Yarcheski, T. J., Cannella, B. L., \& Hanks, M. M. (2006). A metaanalytic study of predictors for loneliness during adolescence. Nursing Research, 55(5), 308-315. https://doi.org/10.1097/00006199-200609000-00003 
Manning, W. D., \& Joyner, K. (2019). Demographic approaches to same-sex relationship dissolution and divorce: Research findings, data challenges, and implications for future research. In A. E. Goldberg \& A. P. Romero (Eds.), LGBTQ divorce and relationship dissolution: Psychological and legal perspectives and implications for practice (pp. 3548). New York, NY: Oxford University Press.

Masi, C. M., Chen, H. Y., Hawkley, L. C., \& Cacioppo, J. T. (2011). A meta-analysis of interventions to reduce loneliness. Personality and Social Psychology Review, 15(3), 219266. https://doi.org/10.1177/1088868310377394

Maslow, A. H. (1943). A theory of human motivation. Psychological Review, 50, 370-396. https://doi.org/10.1037/h0054346

Matthews, K. A., Adler, N. E., Forrest, C. B., \& Stead, W. W. (2016). Collecting psychosocial "vital signs" in electronic health records: Why now? What are they? What's new for psychology?. American Psychologist, 71(6), 497-504. https://doi.org/10.1037/a0040317

Maud, C., Ryan, J., McIntosh, J. E., \& Olsson, C. A. (2018). The role of oxytocin receptor gene (OXTR) DNA methylation (DNAm) in human social and emotional functioning: A systematic narrative review. BMC Psychiatry, 18(1), 1-13. https://doi.org/10.1186/s12888$\underline{018-1740-9}$

McGeough, B. L., \& Sterzing, P. R. (2018). A systematic review of family victimization experiences among sexual minority youth. The Journal of Primary Prevention, 39(5), 491528. https://doi.org/10.1007/s10935-018-0523-X

McPherson, M., Smith-Lovin, L., \& Brashears, M. E. (2006). Social isolation in America: Changes in core discussion networks over two decades. American Sociological Review, 71(3), 353-375. https://doi.org/10.1177/000312240607100301 
Meisters, R., Westra, D., Putrik, P., Bosma, H., Ruwaard, D., \& Jansen, M. (2021). Does loneliness have a cost? A population-wide study of the association between loneliness and healthcare expenditure. International Journal of Public Health, 66, 581286. https://doi.org/10.3389/ijph.2021.581286

Merton, R. K. (1957). The role-set: Problems in sociological theory. The British Journal of Sociology, 8(2), 106-120. https://doi.org/10.2307/587363

Mihalopoulos, C., Le, L. K. D., Chatterton, M. L., Bucholc, J., Holt-Lunstad, J., Lim, M. H., \& Engel, L. (2020). The economic costs of loneliness: A review of cost-of-illness and economic evaluation studies. Social Psychiatry and Psychiatric Epidemiology, 55(7), 823836. https://doi.org/10.1007/s00127-019-01733-7

Mills, J., \& Clark, M. S. (1982). Communal and exchange relationships. Review of Personality and Social Psychology, 3(2), 121-144.

Miyawaki, C. E. (2015). Association of social isolation and health across different racial and ethnic groups of older Americans. Ageing and Society, 35(10), 2201-2228. https://doi.org/10.1017/S0144686X14000890

Moore, S., \& Kawachi, I. (2017). Twenty years of social capital and health research: A glossary. Journal of Epidemiology \& Community Health, 71(5), 513-517. http://dx.doi.org/10.1136/jech-2016-208313

Mosovich, S. T., Boone, R. T., Reichenberg, A., Bansilal, S., Shaffer, J., Dahlman, K., ... Farkouh, M. E. (2008). New insights into the link between cardiovascular disease and depression. International Journal of Clinical Practice, 62(3), 423-432.

https://doi.org/10.1111/j.1742-1241.2007.01640.x 
Mund, M., Freuding, M. M., Möbius, K., Horn, N., \& Neyer, F. J. (2020). The stability and change of loneliness across the life span: A meta-analysis of longitudinal studies. Personality and Social Psychology Review, 24(1), 24-52. https://doi.org/10.1177/1088868319850738

Murray, S. L., Holmes, J. G., \& Griffin, D. W. (1996). The benefits of positive illusions: Idealization and the construction of satisfaction in close relationships. Journal of Personality and Social Psychology, 70(1), 79-98. https://doi.org/10.1037/0022-

3514.70.1.79

Murray, S. L., Holmes, J. G., \& Griffin, D. W. (1996). The self-fulfilling nature of positive illusions in romantic relationships: Love is not blind, but prescient. Journal of Personality and Social Psychology, 71(6), 1155-1180. https://doi.org/10.1037/0022-3514.71.6.1155

Murry, V. M., Brown, P. A., Brody, G. H., Cutrona, C. E., \& Simons, R. L. (2001). Racial discrimination as a moderator of the links among stress, maternal psychological functioning, and family relationships. Journal of Marriage and Family, 63(4), 915-926. https://doi.org/10.1111/j.1741-3737.2001.00915.x

Murthy, V. (2017). Work and the loneliness epidemic. Harvard Business Review. Retrieved from https://hbr.org/2017/09/work-and-the-loneliness-epidemic

Myers, S. M., Voigt, R. G., Colligan, R. C., Weaver, A. L., Storlie, C. B., Stoeckel, R. E., ... Katusic, S. K. (2019). Autism spectrum disorder: Incidence and time trends over two decades in a population-based birth cohort. Journal of Autism and Developmental Disorders, 49(4), 1455-1474. https://doi.org/10.1007/s10803-018-3834-0 
National Academies of Sciences, Engineering, and Medicine (2020). Social isolation and loneliness in older adults: Opportunities for the health care system. Washington, DC: The National Academies Press.

Ng, S. M., Chan, C. L., Leung, P. P., Chan, C. H., \& Yau, J. K. (2008). Beyond survivorship: Achieving a harmonious dynamic equilibrium using a Chinese medicine framework in health and mental health. Social Work in Mental Health, 7(1-3), 62-81. https://doi.org/10.1080/15332980802072405

Noack, H. (1987). Concepts of health and health promotion. In T. Abelin, Z. J. Brezinski, \& V. Carstairs (Eds), Measurement of health promotion and protection (European Series Number 22, pp. 5-28). Copenhagen: WHO Regional Publications.

Noone, C., McSharry, J., Smalle, M., Burns, A., Dwan, K., Devane, D., \& Morrissey, E. C. (2020). Video calls for reducing social isolation and loneliness in older people: A rapid review. Cochrane Database of Systematic Reviews, 5. https://doi.org/10.1002/14651858.CD013632

Ohme, J., Abeele, M. M. V., Van Gaeveren, K., Durnez, W., \& De Marez, L. (2020). Staying informed and bridging "social distance": Smartphone news use and mobile messaging behaviors of Flemish adults during the first weeks of the COVID-19 pandemic. Socius, 6 . https://doi.org/10.1177/2378023120950190

Oishi, S. (2010). The psychology of residential mobility: Implications for the self, social relationships, and well-being. Perspectives on Psychological Science, 5(1), 5-21. https://doi.org/10.1177/1745691609356781 
Olsen, E. O. M., Kann, L., Vivolo-Kantor, A., Kinchen, S., \& McManus, T. (2014). School violence and bullying among sexual minority high school students, 2009-2011. Journal of Adolescent Health, 55(3), 432-438. https://doi.org/10.1016/j.jadohealth.2014.03.002

O'Reilly, J., Robinson, S. L., Berdahl, J. L., \& Banki, S. (2015). Is negative attention better than no attention? The comparative effects of ostracism and harassment at work. Organization Science, 26(3), 774-793. https://doi.org/10.1287/orsc.2014.0900

Pantell, M., Rehkopf, D., Jutte, D., Syme, S. L., Balmes, J., \& Adler, N. (2013). Social isolation: A predictor of mortality comparable to traditional clinical risk factors. American Journal of Public Health, 103(11), 2056-2062. https://doi.org/10.2105/AJPH.2013.301261

Pearlin, L. I. (1980). Life strains and psychological distress among adults. In N. J. Smelser \& E. H. Erikson (Eds.), Themes of work and love in adulthood (pp. 174-192). Cambridge, MA: Harvard University Press.

Pearlin, L. I., \& Schooler, C. (1978). The structure of coping. Journal of Health and Social Behavior, 19(1), 2-21. https://doi.org/10.2307/2136319

Peplau, L. A., \& Perlman, D. (1982). Perspectives on loneliness. In L. A. Peplau \& D. Perlman (Eds.), Loneliness: A sourcebook of current theory, research and therapy (pp. 1-18). New York, NY: Wiley.

Pescosolido, B. A., \& Levy, J. A. (2002). The role of social networks in health, illness, disease and healing: The accepting present, the forgotten past, and the dangerous potential for a complacent future. In J. A. Levy \& B. A. Pescosolido (Eds.). Social networks and health (pp.3-25). Amsterdam, NL: Elsevier Science. https://doi.org/10.1016/S1057$\underline{6290(02) 80019-5}$ 
Perissinotto, C. M., Cenzer, I. S., \& Covinsky, K. E. (2012). Loneliness in older persons: A predictor of functional decline and death. Archives of Internal Medicine, 172(14), 10781084. https://doi.org/10.1001/archinternmed.2012.1993

Phelan, J. C., Link, B. G., \& Tehranifar, P. (2010). Social conditions as fundamental causes of health inequalities: Theory, evidence, and policy implications. Journal of Health and Social Behavior, 51(1), S28-S40. https://doi.org/10.1177/0022146510383498

Picard, M., \& Sandi, C. (2021). The social nature of mitochondria: Implications for human health. Neuroscience \& Biobehavioral Reviews, 120, 595-610. https://doi.org/10.1016/j.neubiorev.2020.04.017

Pietromonaco, P. R., \& Collins, N. L. (2017). Interpersonal mechanisms linking close relationships to health. American Psychologist, 72(6), 531-542. https://doi.org/10.1037/amp0000129

Plöderl, M., Sellmeier, M., Fartacek, C., Pichler, E. M., Fartacek, R., \& Kralovec, K. (2014). Explaining the suicide risk of sexual minority individuals by contrasting the minority stress model with suicide models. Archives of Sexual Behavior, 43(8), 1559-1570. https://doi.org/10.1007/s10508-014-0268-4

Pollet, T. V., Roberts, S. G., \& Dunbar, R. I. (2011). Extraverts have larger social network layers: But do not feel emotionally closer to individuals at any layer. Journal of Individual Differences, 32(3), 161-169. https://doi.org/10.1027/1614-0001/a000048

Porcelli, S., Van Der Wee, N., van der Werff, S., Aghajani, M., Glennon, J. C., van Heukelum, S., ... Serretti, A. (2019). Social brain, social dysfunction and social withdrawal. Neuroscience \& Biobehavioral Reviews, 97, 10-33. https://doi.org/10.1016/j.neubiorev.2018.09.012 
Poscia, A., Stojanovic, J., La Milia, D. I., Duplaga, M., Grysztar, M., Moscato, U., ... Magnavita, N. (2018). Interventions targeting loneliness and social isolation among the older people: An update systematic review. Experimental Gerontology, 102, 133-144. https://doi.org/10.1016/j.exger.2017.11.017

Poštuvan, V., Podlogar, T., Šedivy, N. Z., \& De Leo, D. (2019). Suicidal behaviour among sexual-minority youth: A review of the role of acceptance and support. The Lancet Child \& Adolescent Health, 3(3), 190-198. https://doi.org/10.1016/S2352-4642(18)30400-0

Poteat, V. P., Birkett, M., Turner, B., Wang, X., \& Phillips II, G. (2020). Changes in victimization risk and disparities for heterosexual and sexual minority youth: Trends from 2009 to 2017. Journal of Adolescent Health, 66(2), 202-209. https://doi.org/10.1016/j.jadohealth.2019.08.009

Poulain, M., Herm, A., \& Pes, G. (2013). The Blue Zones: Areas of exceptional longevity around the world. Vienna Yearbook of Population Research, 11, 87-108. https://doi.org/10.1553/populationyearbook2013s87

Priest, N., Perry, R., Ferdinand, A., Kelaher, M., \& Paradies, Y. (2017). Effects over time of selfreported direct and vicarious racial discrimination on depressive symptoms and loneliness among Australian school students. BMC Psychiatry, 17(1), 1-11. https://doi.org/10.1186/s12888-017-1216-3

Pu, L., Moyle, W., Jones, C., \& Todorovic, M. (2019). The effectiveness of social robots for older adults: A systematic review and meta-analysis of randomized controlled studies. The Gerontologist, 59(1), e37-e51. https://doi.org/10.1093/geront/gny046

Putnam, R. D. (1994). Social capital and public affairs. Bulletin of the American Academy of Arts and Sciences, 47(8), 5-19. https://doi.org/10.2307/3824796 
Putnam, R. D. (1995). Tuning in, tuning out: The strange disappearance of social capital in America. PS: Political Science \& Politics, 28(4), 664-684. https://doi.org/10.2307/420517

Putnam, R. D. (2000). Bowling alone: The collapse and revival of American community. New York, NY: Simon and Schuster.

Quadt, L., Esposito, G., Critchley, H. D., \& Garfinkel, S. N. (2020). Brain-body interactions underlying the association of loneliness with mental and physical health. Neuroscience \& Biobehavioral Reviews, 116, 283-300. https://doi.org/10.1016/j.neubiorev.2020.06.015

Qualter, P., Vanhalst, J., Harris, R., Van Roekel, E., Lodder, G., Bangee, M., ... Verhagen, M. (2015). Loneliness across the life span. Perspectives on Psychological Science, 10(2), 250264. https://doi.org/10.1177/1745691615568999

Quintana, D. S., Smerud, K. T., Andreassen, O. A., \& Djupesland, P. G. (2018). Evidence for intranasal oxytocin delivery to the brain: Recent advances and future perspectives.

Therapeutic Delivery, 9(7), 515-525. https://doi.org/10.4155/tde-2018-0002

Raley, R. K., Sweeney, M. M., \& Wondra, D. (2015). The growing racial and ethnic divide in U.S. marriage patterns. The Future of Children, 25(2), 89-109. https://doi.org/10.1353/foc.2015.0014

Ramsay, D. S., \& Woods, S. C. (2014). Clarifying the roles of homeostasis and allostasis in physiological regulation. Psychological Review, 121(2), 225-247. https://doi.org/10.1037/a0035942

Renne, K. S. (1974). Measurement of social health in a general population survey. Social Science Research, 3(1), 25-44. https://doi.org/10.1016/0049-089X(74)90017-9

Reinhardt, G., Vidovic, D., \& Hammerton, C. (2020). Understanding loneliness: A systematic review of the impact of social prescribing initiatives on loneliness. Perspectives in Public 
Health. Retrieved from

http://repository.essex.ac.uk/28754/5/PerspPublicHealth_SocialPrescribing-Loneliness.pdf

Reis, H. T. (2007). Steps toward the ripening of relationship science. Personal Relationships, 14(1), 1-23. https://doi.org/10.1111/j.1475-6811.2006.00139.x

Reis, H. T. (2012). Perceived partner responsiveness as an organizing theme for the study of relationships and well-being. In L. Campbell \& T. J. Loving (Eds.), Interdisciplinary research on close relationships: The case for integration (pp. 27-52). Washington, DC: American Psychological Association.

Reis, H. T., Clark, M. S., \& Holmes, J. G. (2004). Perceived partner responsiveness as an organizing construct in the study of intimacy and closeness. In D. J. Mashek \& A. P. Aron (Eds.), Handbook of closeness and intimacy (pp. 201-225). Mahwah, NJ: Erlbaum.

Reis, H. T., \& Franks, P. (1994). The role of intimacy and social support in health outcomes: Two processes or one?. Personal Relationships, 1(2), 185-197. https://doi.org/10.1111/j.1475-6811.1994.tb00061.x

Rempel, J. K., Holmes, J. G., \& Zanna, M. P. (1985). Trust in close relationships. Journal of Personality and Social Psychology, 49(1), 95-112. https://doi.org/10.1037/0022$\underline{3514.49 .1 .95}$

Richman, L. S., Martin, J., \& Guadagno, J. (2016). Stigma-based rejection and the detection of signs of acceptance. Social Psychological and Personality Science, 7(1), 53-60. https://doi.org/10.1177/1948550615598376

Robles, T. F., Slatcher, R. B., Trombello, J. M., \& McGinn, M. M. (2014). Marital quality and health: A meta-analytic review. Psychological Bulletin, 140(1), 140-187. https://doi.org/10.1037/a0031859 
Rodgers, J., Valuev, A. V., Hswen, Y., \& Subramanian, S. V. (2019). Social capital and physical health: An updated review of the literature for 2007-2018. Social Science \& Medicine, 236, 112360. https://doi.org/10.1016/j.socscimed.2019.112360

Rook, K. S. (2015). Social networks in later life: Weighing positive and negative effects on health and well-being. Current Directions in Psychological Science, 24(1), 45-51. https://doi.org/10.1177/0963721414551364

Rose, G. (1985). Sick individuals and sick populations. International Journal of Epidemiology, $14,32-8$.

Rusbult, C. E. (1980). Commitment and satisfaction in romantic associations: A test of the investment model. Journal of Experimental Social Psychology, 16(2), 172-186. https://doi.org/10.1016/0022-1031(80)90007-4

Russell, D., Cutrona, C. E., Rose, J., \& Yurko, K. (1984). Social and emotional loneliness: an examination of Weiss's typology of loneliness. Journal of Personality and Social Psychology, 46(6), 1313-1321. https://doi.org/10.1037/0022-3514.46.6.1313

Russell, R. D. (1973). Social health: An attempt to clarify this dimension of well-being. International Journal of Health Education, 16(2), 74-82.

Ryff, C. D., \& Singer, B. (2000). Interpersonal flourishing: A positive health agenda for the new millennium. Personality and Social Psychology Review, 4(1), 30-44. https://doi.org/10.1207/s15327957pspr0401_4

Sani, F., Herrera, M., Wakefield, J. R., Boroch, O., \& Gulyas, C. (2012). Comparing social contact and group identification as predictors of mental health. British Journal of Social Psychology, 51(4), 781-790. https://doi.org/10.1111/j.2044-8309.2012.02101.x 
Sargisson, L. (2012). Second-wave cohousing: A modern utopia?. Utopian Studies, 23(1), 28-56. https://doi.org/10.5325/utopianstudies.23.1.0028

Schieman, S., Glavin, P., \& Milkie, M. A. (2009). When work interferes with life: Worknonwork interference and the influence of work-related demands and resources. American Sociological Review, 74(6), 966-988. https://doi.org/10.1177/000312240907400606

Schneiderman, I., Zagoory-Sharon, O., Leckman, J. F., \& Feldman, R. (2012). Oxytocin during the initial stages of romantic attachment: Relations to couples' interactive reciprocity. Psychoneuroendocrinology, 37(8), 1277-1285. https://doi.org/10.1016/j.psyneuen.2011.12.021

Schulkin, J. (2011). Social allostasis: Anticipatory regulation of the internal milieu. Frontiers in Evolutionary Neuroscience, 2, 111. https://doi.org/10.3389/fnevo.2010.00111

Seibert, S. E., Kraimer, M. L., \& Liden, R. C. (2001). A social capital theory of career success. Academy of Management Journal, 44(2), 219-237. https://doi.org/10.5465/3069452

Seiffe-Krenke, I. (2006). Leaving home or still in the nest? Parent-child relationships and psychological health as predictors of different leaving home patterns. Developmental Psychology, 42(5), 864-876. https://doi.org/10.1037/0012-1649.42.5.864

Sen, A. (2008). Why and how is health a human right?. The Lancet, 372(9655), 2010. https://doi.org/10.1016/S0140-6736(08)61784-5

Shah, J. (2003). Automatic for the people: How representations of significant others implicitly affect goal pursuit. Journal of Personality and Social Psychology, 84(4), 661-681. https://doi.org/10.1037/0022-3514.84.4.661

Shalev, S. (2009). Supermax: Controlling risk through solitary confinement. Collumpton, UK: Willan Publishing. 
Shankar, A., Hamer, M., McMunn, A., \& Steptoe, A. (2013). Social isolation and loneliness: Relationships with cognitive function during 4 years of follow-up in the English Longitudinal Study of Ageing. Psychosomatic Medicine, 75(2), 161-170. https://doi.org/10.1097/PSY.0b013e31827f09cd

Shiell, A., Hawe, P., \& Kavanagh, S. (2020). Evidence suggests a need to rethink social capital and social capital interventions. Social Science \& Medicine, 257, 111930. https://doi.org/10.1016/j.socscimed.2018.09.006

Shirai, K. (2020). Social determinants of health on the island of Okinawa. In E. Brunner, N. Cable, \& H. Iso (Eds.), Health in Japan: Social epidemiology of Japan since the 1964 Tokyo Olympics (pp. 297-312). Oxford, UK: Oxford University Press.

Sieber, S. D. (1974). Toward a theory of role accumulation. American Sociological Review, 39(4), 567-578. https://doi.org/10.2307/2094422

Sigerist, H. E. (1943). Civilization and disease. Ithaca, NY: Cornell University Press.

Simpson, J. A., Collins, W. A., \& Salvatore, J. E. (2011). The impact of early interpersonal experience on adult romantic relationship functioning: Recent findings from the Minnesota longitudinal study of risk and adaptation. Current Directions in Psychological Science, 20(6), 355-359. https://doi.org/10.1177/0963721411418468

Singer, T., Seymour, B., O'doherty, J., Kaube, H., Dolan, R. J., \& Frith, C. D. (2004). Empathy for pain involves the affective but not sensory components of pain. Science, 303(5661), 1157-1162. https://doi.org/10.1126/science.1093535

Singh-Manoux, A., Marmot, M. G., \& Adler, N. E. (2005). Does subjective social status predict health and change in health status better than objective status?. Psychosomatic Medicine, 67(6), 855-861. https://doi.org/10.1097/01.psy.0000188434.52941.a0 
Slavich, G. M. (2020). Social safety theory: A biologically based evolutionary perspective on life stress, health, and behavior. Annual Review of Clinical Psychology, 16, 265-295. https://doi.org/10.1146/annurev-clinpsy-032816-045159

Slavich, G. M., \& Irwin, M. R. (2014). From stress to inflammation and major depressive disorder: A social signal transduction theory of depression. Psychological Bulletin, 140(3), 774-815. https://doi.org/10.1037/a0035302

Snell, K. D. M. (2017). The rise of living alone and loneliness in history. Social History, 42(1), 2-28. https://doi.org/10.1080/03071022.2017.1256093

Snyder-Mackler, N., Burger, J.R., Gaydosh, L., Belsky, D.W., Noppert, G.A., Campos, F.A., . . Tung, J. (2020). Social determinants of health and survival in humans and other animals. Science, 368(6493), eaax9553. https://doi.org/10.1126/science.aax9553

South, J., Higgins, T. J., Woodall, J., \& White, S. M. (2008). Can social prescribing provide the missing link?. Primary Health Care Research \& Development, 9(4), 310-318. https://doi.org/10.1017/S146342360800087X

Sperr, E. (2016). PubMed by Year. Available from http://esperr.github.io/pubmed-by-year/

Steffens, N. K., LaRue, C. J., Haslam, C., Walter, Z. C., Cruwys, T., Munt, K. A., ... Tarrant, M. (2021). Social identification-building interventions to improve health: A systematic review and meta-analysis. Health Psychology Review, 15(1), 85-112. https://doi.org/10.1080/17437199.2019.1669481

Sterling, P., \& Eyer, J. (1988). Allostasis: A new paradigm to explain arousal pathology. In S. Fisher \& J. Reason (Eds.), Handbook of life stress, cognition and health (pp. 629-649). New York: Wiley. 
Stern, J. (2020). This is not a normal mental-health disaster. The Atlantic. Retrieved from https://www.theatlantic.com/health/archive/2020/07/coronavirus-special-mental-healthdisaster/613510/

Stokes, J. P. (1983). Predicting satisfaction with social support from social network structure. American Journal of Community Psychology, 11(2), 141-152. https://doi.org/10.1007/BF00894363

Suanet, B., \& van Tilburg, T. G. (2019). Loneliness declines across birth cohorts: The impact of mastery and self-efficacy. Psychology and Aging, 34(8), 1134-1143. https://doi.org/10.1037/pag0000357

Suls, J. M., Luger, T., \& Martin, R. (2010). The biopsychosocial model and the use of theory in health psychology. In J. M. Suls, K. W. Davidson, \& R. M. Kaplan (Eds.), Handbook of health psychology and behavioural medicine (pp. 15-27). New York, NY: Guilford Press.

Suls, J., \& Rothman, A. (2004). Evolution of the biopsychosocial model: Prospects and challenges for health psychology. Health Psychology, 32, 119-125.

https://doi.org/10.1037/0278-6133.23.2.119

Susser, M. (1993). Health as a human right: An epidemiologist's perspective on the public health. American Journal of Public Health, 83(3), 418-426. https://doi.org/10.2105/AJPH.83.3.418

Susser, M., \& Susser, E. (1996). Choosing a future for epidemiology: I. Eras and paradigms. American Journal of Public Health, 86(5), 668-673. https://doi.org/10.2105/AJPH.86.5.668 
Sutcliffe, A., Dunbar, R., Binder, J., \& Arrow, H. (2012). Relationships and the social brain: Integrating psychological and evolutionary perspectives. British Journal of Psychology, 103(2), 149-168. https://doi.org/10.1111/j.2044-8295.2011.02061.x

Swann, W. B., Jr. (1983). Self-verification: Bringing social reality into harmony with the self. In J. Suls \& A. G. Greenwald (Eds.), Social psychological perspectives on the self(Vol. 2, pp. 33-66). Hillsdale, NJ: Erlbaum.

Swickert, R. J., Rosentreter, C. J., Hittner, J. B., \& Mushrush, J. E. (2002). Extraversion, social support processes, and stress. Personality and Individual Differences, 32(5), 877-891. https://doi.org/10.1016/S0191-8869(01)00093-9

Tajfel, H., \& Turner, J. C. (1979). An integrative theory of intergroup conflict. In W. G. Austin \& S. Worchel (Eds.), The social psychology of intergroup relations (pp. 33-47). Monterey, CA: Brooks/Cole.

Taylor, S. E. (2011). Social support: A review. In H. S. Friedman (Ed.), The Oxford handbook of health psychology (pp. 189-214). New York, NY: Oxford University Press.

Templin, C., Ghadri, J. R., Diekmann, J., Napp, L. C., Bataiosu, D. R., Jaguszewski, M., ... Lüscher, T. F. (2015). Clinical features and outcomes of Takotsubo (stress) cardiomyopathy. New England Journal of Medicine, 373(10), 929-938. https://doi.org/10.1056/NEJMoa1406761

Thoits, P. A. (2011). Mechanisms linking social ties and support to physical and mental health. Journal of Health and Social Behavior, 52(2), 145-161. https://doi.org/10.1177/0022146510395592 
Thomas, W. I., \& Thomas, D. S. (1928). The methodology of behavior study. In The child in America: Behavior problems and programs (pp. 553-576). New York, NY: Alfred A. Knopf.

Thorsen, M. L. (2017). The adolescent family environment and cohabitation across the transition to adulthood. Social Science Research, 64, 249-262. https://doi.org/10.1016/j.ssresearch.2016.10.007

Timmons, A. C., Margolin, G., \& Saxbe, D. E. (2015). Physiological linkage in couples and its implications for individual and interpersonal functioning: A literature review. Journal of Family Psychology, 29(5), 720-731. https://doi.org/10.1037/fam0000115

Tomaka, J., Thompson, S., \& Palacios, R. (2006). The relation of social isolation, loneliness, and social support to disease outcomes among the elderly. Journal of Aging and Health, 18(3), 359-384. https://doi.org/10.1177/0898264305280993

Tov, W., Nai, Z. L., \& Lee, H. W. (2016). Extraversion and agreeableness: Divergent routes to daily satisfaction with social relationships. Journal of Personality, 84(1), 121-134. https://doi.org/10.1111/jopy.12146

Trail, T. E., Goff, P. A., Bradbury, T. N., \& Karney, B. R. (2012). The costs of racism for marriage: How racial discrimination hurts, and ethnic identity protects, newlywed marriages among Latinos. Personality and Social Psychology Bulletin, 38(4), 454-465. https://doi.org/10.1177/0146167211429450

Triandis, H. C. (1995). Individualism and collectivism. Boulder, CO: Westview.

Turner, J. B., \& Turner, R. J. (2013). Social relations, social integration, and social support. In C. Aneshensel, J. Phelan, \& A. Bierman (Eds.), Handbook of the sociology of mental health (pp. 341-356). Dordrecht, NL: Springer. 
Turner, J. C., Hogg, M. A., Oakes, P. J., Reicher, S. D., \& Wetherell, M. S. (1987).

Rediscovering the social group: A self-categorization theory. Oxford, UK: Blackwell.

Twenge, J. M., Campbell, W. K., \& Freeman, E. C. (2012). Generational differences in young adults' life goals, concern for others, and civic orientation, 1966-2009. Journal of Personality and Social Psychology, 102(5), 1045-1062. https://doi.org/10.1037/a0027408

Uchino, B. N., Bowen, K., Carlisle, M., \& Birmingham, W. (2012). Psychological pathways linking social support to health outcomes: A visit with the "ghosts" of research past, present, and future. Social Science \& Medicine, 74(7), 949-957. https://doi.org/10.1016/j.socscimed.2011.11.023

Ulmer-Yaniv, A., Avitsur, R., Kanat-Maymon, Y., Schneiderman, I., Zagoory-Sharon, O., \& Feldman, R. (2016). Affiliation, reward, and immune biomarkers coalesce to support social synchrony during periods of bond formation in humans. Brain, Behavior, and Immunity, 56, 130-139. https://doi.org/10.1016/j.bbi.2016.02.017

Umberson, D., \& Montez, J. K. (2010). Social relationships and health: A flashpoint for health policy. Journal of Health and Social Behavior, 51(1), S54-S66. https://doi.org/10.1177/0022146510383501

Umberson, D., Thomeer, M. B., Williams, K., Thomas, P. A., \& Liu, H. (2016). Childhood adversity and men's relationships in adulthood: Life course processes and racial disadvantage. Journals of Gerontology Series B: Psychological Sciences and Social Sciences, 71(5), 902-913. https://doi.org/10.1093/geronb/gbv091

Unger, D. G., \& Powell, D. R. (1980). Supporting families under stress: The role of social networks. Family Relations, 29(4), 566-574. https://doi.org/10.2307/584473 
Utz, R. L., Carr, D., Nesse, R., \& Wortman, C. B. (2002). The effect of widowhood on older adults' social participation: An evaluation of activity, disengagement, and continuity theories. The Gerontologist, 42(4), 522-533. https://doi.org/10.1093/geront/42.4.522

Valtorta, N. K., Kanaan, M., Gilbody, S., \& Hanratty, B. (2016). Loneliness, social isolation and social relationships: What are we measuring? A novel framework for classifying and comparing tools. BMJ Open, 6(4), e010799. http://dx.doi.org/10.1136/bmjopen-2015$\underline{010799}$

Van Anders, S. M., Goldey, K. L., \& Kuo, P. X. (2011). The steroid/peptide theory of social bonds: Integrating testosterone and peptide responses for classifying social behavioral contexts. Psychoneuroendocrinology, 36(9), 1265-1275. https://doi.org/10.1016/j.psyneuen.2011.06.001

Van Dorn, A., Cooney, R. E., \& Sabin, M. L. (2020). COVID-19 exacerbating inequalities in the US. Lancet, 395(10232), 1243-1244. https://doi.org/10.1016/S0140-6736(20)30893-X

Vanhalst, J., Luyckx, K., Scholte, R. H., Engels, R. C., \& Goossens, L. (2013). Low self-esteem as a risk factor for loneliness in adolescence: Perceived-but not actual-social acceptance as an underlying mechanism. Journal of Abnormal Child Psychology, 41(7), 1067-1081. https://doi.org/10.1007/s10802-013-9751-y

Vanhalst, J., Luyckx, K., Van Petegem, S., \& Soenens, B. (2018). The detrimental effects of adolescents' chronic loneliness on motivation and emotion regulation in social situations. Journal of Youth and Adolescence, 47(1), 162-176. https://doi.org/10.1007/s10964-017$\underline{0686-4}$ 
Van Orden, K. A., Witte, T. K., Cukrowicz, K. C., Braithwaite, S. R., Selby, E. A., \& Joiner, T. E., Jr. (2010). The interpersonal theory of suicide. Psychological Review, 117(2), 575600. https://doi.org/10.1037/a0018697

van Roekel, E., Goossens, L., Verhagen, M., Wouters, S., Engels, R. C., \& Scholte, R. H. (2014). Loneliness, affect, and adolescents' appraisals of company: An experience sampling method study. Journal of Research on Adolescence, 24(2), 350-363. https://doi.org/10.1111/jora.12061

van Tilburg, T., Steinmetz, S., Stolte, E., van der Roest, H., \& de Vries, D. H. (2020). Loneliness and mental health during the COVID-19 pandemic: A study among Dutch older adults. Journals of Gerontology Series B: Psychological Sciences and Social Sciences, 1-7. https://doi.org/10.1093/geronb/gbaa111

Victor, C. R., Burholt, V., \& Martin, W. (2012). Loneliness and ethnic minority elders in Great Britain: An exploratory study. Journal of Cross-Cultural Gerontology, 27(1), 65-78. https://doi.org/10.1007/s10823-012-9161-6

Wade, D. T., \& Halligan, P. W. (2004). Do biomedical models of illness make for good healthcare systems?. BMJ, 329(7479), 1398-1401. https://doi.org/10.1136/bmj.329.7479.1398

Wager, T. D., Atlas, L. Y., Botvinick, M. M., Chang, L. J., Coghill, R. C., Davis, K. D., ... Yarkoni, T. (2016). Pain in the ACC?. Proceedings of the National Academy of Sciences, 113(18), E2474-E2475. https://doi.org/10.1073/pnas.1600282113

Waite, L. J. (2018). Social well-being and health in the older population: Moving beyond social relationships. In M. D. Hayward \& M. K. Majmundar (Eds.), Future directions for the 
demography of aging: Proceedings of a workshop (pp. 99-130). Washington, DC: National Academies Press.

Walen, H. R., \& Lachman, M. E. (2000). Social support and strain from partner, family, and friends: Costs and benefits for men and women in adulthood. Journal of Social and Personal Relationships, 17(1), 5-30. https://doi.org/10.1177/0265407500171001

Wallace, B. A., \& Shapiro, S. L. (2006). Mental balance and well-being: Building bridges between Buddhism and Western psychology. American Psychologist, 61(7), 690-701. https://doi.org/10.1037/0003-066X.61.7.690

Wallis, W. (2021). The UK mental health crisis coming in Covid's wake. Financial Times. Retrieved from https://www.ft.com/content/88c8f248-acde-42cb-bc2a-bb9a95c031d9

Ware Jr, J. E. (1995). The status of health assessment 1994. Annual Review of Public Health, 16(1), 327-354. https://doi.org/10.1146/annurev.pu.16.050195.001551

Ware Jr, J. E., Brook, R. H., Davies, A. R., \& Lohr, K. N. (1981). Choosing measures of health status for individuals in general populations. American Journal of Public Health, 71(6), 620-625. https://doi.org/10.2105/AJPH.71.6.620

Warner, E., Sutton, E., \& Andrews, F. (2020). Cohousing as a model for social health: A scoping review. Cities \& Health, 1-13. https://doi.org/10.1080/23748834.2020.1838225

Watt, S. E., \& Badger, A. J. (2009). Effects of social belonging on homesickness: An application of the belongingness hypothesis. Personality and Social Psychology Bulletin, 35(4), 516530. https://doi.org/10.1177/0146167208329695

Wethington, E., Moen, P., Glasgow, N., \& Pillemer, K. (2000). Multiple roles, social integration and health. In K. Pillemer, P. Moen, E. Wethington, \& N. Glasgow (Eds.), Social integration in the second half of life (pp. 48-71). Baltimore, MD: Johns Hopkins Press. 
Whisman, M. A., \& Uebelacker, L. A. (2009). Prospective associations between marital discord and depressive symptoms in middle-aged and older adults. Psychology and Aging, 24(1), 184-189. https://doi.org/10.1037/a0014759

Whooley, M. A., \& Wong, J. M. (2013). Depression and cardiovascular disorders. Annual Review of Clinical Psychology, 9, 327-354. https://doi.org/10.1146/annurev-clinpsy$\underline{050212-185526}$

Williamson, H. C. (2020). Early effects of the COVID-19 pandemic on relationship satisfaction and attributions. Psychological Science, 31(12), 1479-1487. https://doi.org/10.1177/0956797620972688

Wolf, L. D., \& Davis, M. C. (2014). Loneliness, daily pain, and perceptions of interpersonal events in adults with fibromyalgia. Health Psychology, 33(9), 929-937. https://doi.org/10.1037/hea0000059

World Health Organization (1948). Constitution of the World Health Organization. Geneva: World Health Organization.

Wrzus, C., Hänel, M., Wagner, J., \& Neyer, F. J. (2013). Social network changes and life events across the life span: A meta-analysis. Psychological Bulletin, 139(1), 53-80. https://doi.org/10.1037/a0028601

Yum, J. O. (1988). The impact of Confucianism on interpersonal relationships and communication patterns in East Asia. Communications Monographs, 55(4): 374-388. https://doi.org/10.1080/03637758809376178

Zhang, M., Barreto, M., \& Doyle, D. (2020). Stigma-based rejection experiences affect trust in others. Social Psychological and Personality Science, 11(3), 308-316. https://doi.org/10.1177/1948550619829057 


\section{Table 1}

Definitions of Social Health/Well-Being in Prior Literature across Disciplines

\begin{tabular}{ll}
\hline Russell (1973) & p. $75 \quad$ That dimension of an individual's well-being that \\
& concerns how he gets along with other people, how \\
& other people react to him, and how he interacts with \\
& social institutions and societal mores." \\
Renne (1974) & p. $43 \quad$ "The degree to which an individual is a functioning \\
p. 20 & $\quad$ "The quantity and quality of an individual's \\
interpersonal ties and extent of involvement with the &
\end{tabular}

Donald \& Ware (1982)

p. 6

"The quantity and quality of social contacts and social resources."

Larson (1993)

p. 294 "A combination of satisfaction with relationships, performance in social roles and adjustment to one's environment... [as well as] the number of contacts in one's social network and satisfaction with those contacts.”

Keyes \& Shapiro (2004) $\quad$ p. $350 \quad$ “An individual's self-report of the quality of his or her relationship with other people, the neighborhood, and the community."

Castel et al. (2008) p. $738 \quad$ "Perceived well-being regarding social activities and relationships, including the ability to relate to 
individuals, groups, communities, and society as a

whole."

Feeney \& Collins (2014) $\quad$ p. $3 \quad$ "Deep and meaningful human connections, positive interpersonal expectations, a prosocial orientation toward others, faith in others/humanity."

Waite (2018) p. 100 "Adequate and well-functioning social relationships, adequate social support, little or no social strain, some social participation, social inclusion in one's society, strong and well-functioning social networks, and, perhaps, sexuality as one desires." 


\section{Figure 1}

Tripartite Model of Health, Incorporating Physical, Psychological and Social Health, Situated

Within the Human Body (and Mind)

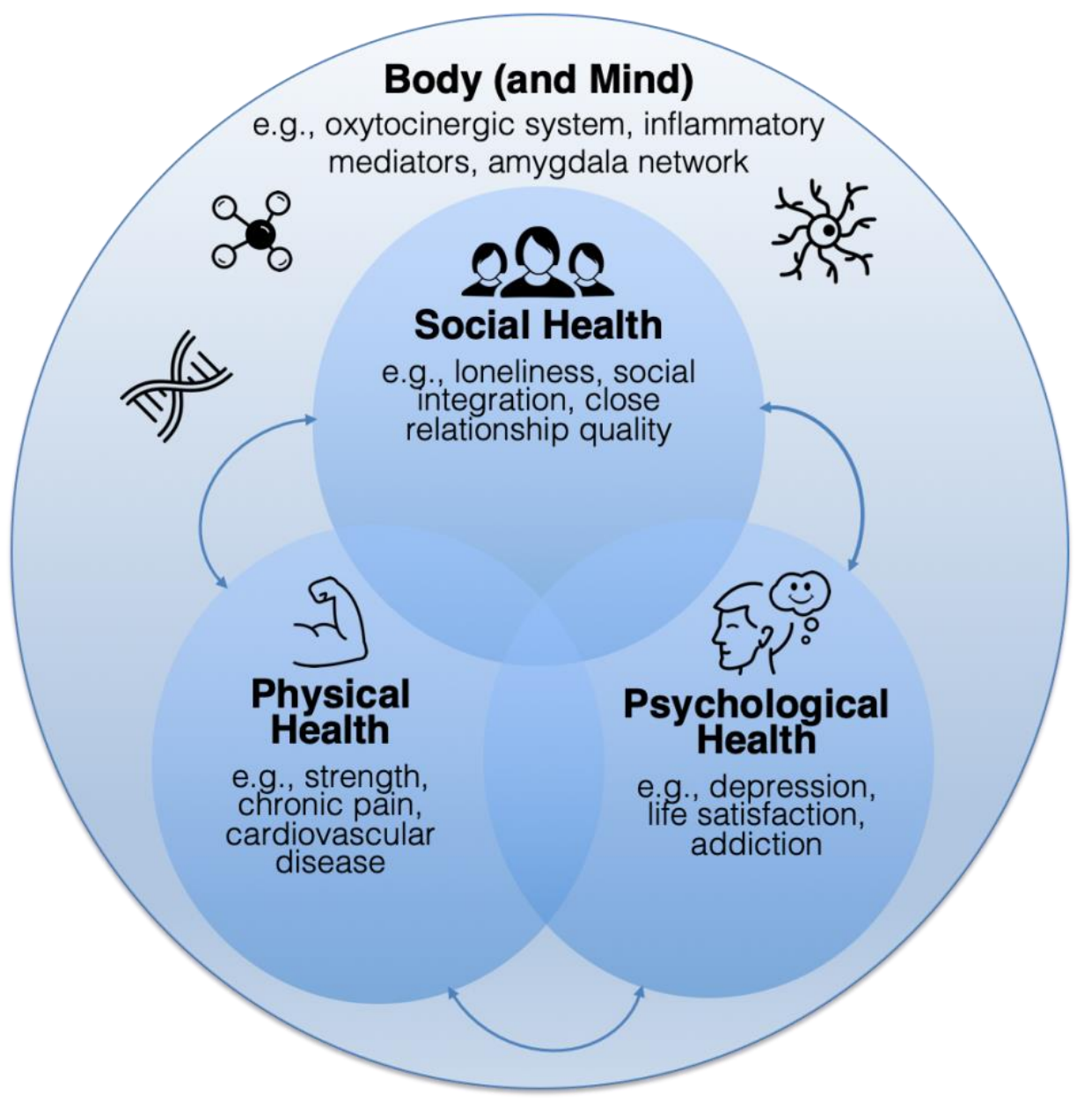




\section{Figure 2}

Proportion of Articles in PubMed Containing the Term "Social Relationships" by Year from 1945-2020 (http://esperr.github.io/pubmed-by-year/)

Results per 100,000 citations in PubMed

proportion for each search by year, 1945 to 2020

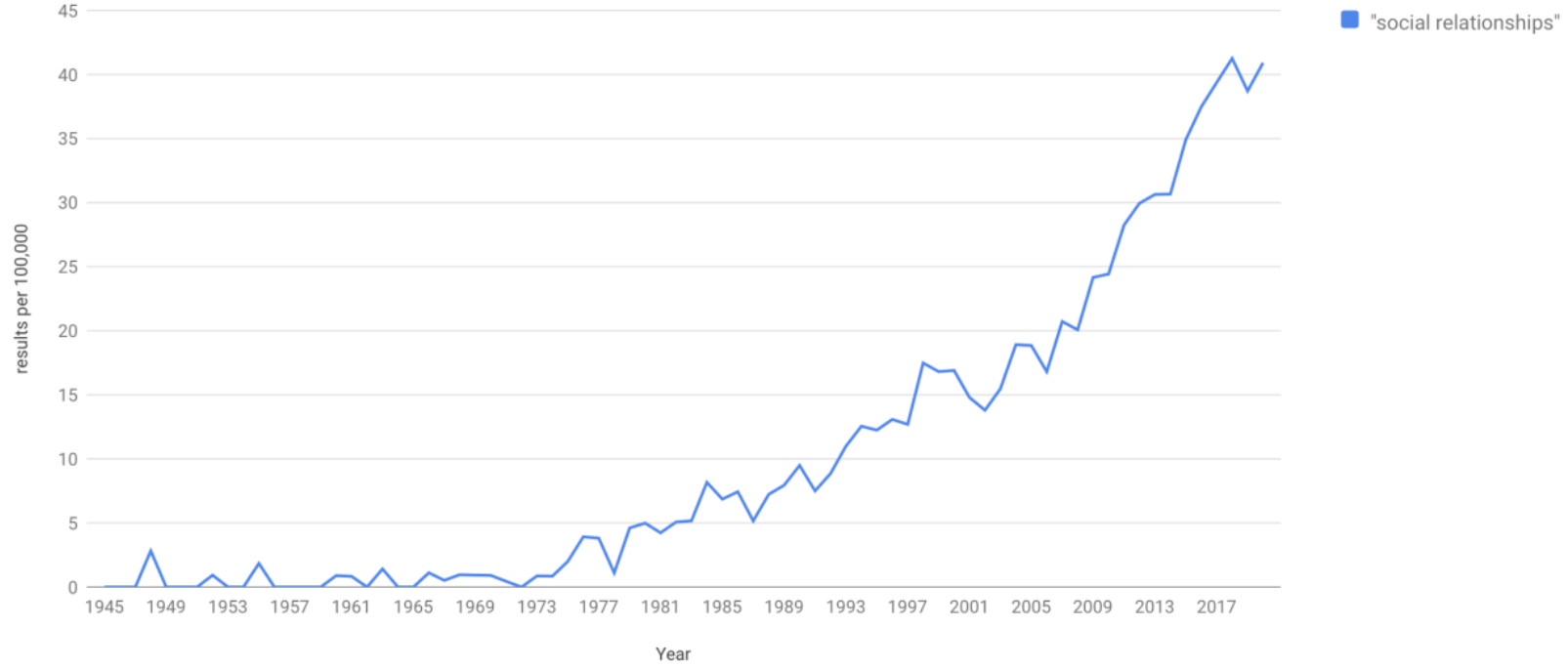

